\title{
A 3D electropolymerized thin film based on an isoporphyrin and on a pyridine end-decorated molybdenum(II) halide cluster: photoelectrochemical and impedance properties
}

\author{
Yiming Liang, ${ }^{a}$ Maxim N. Sokolov, ${ }^{b}$ Maxim A. Mikhaylov, ${ }^{b}$ Helen Ibrahim, ${ }^{c}$ Michel \\ Goldmann, ${ }^{\mathrm{c}, \mathrm{d}}$ Sylvie Choua, ${ }^{\mathrm{a}}$ Nolwenn Le Breton, ${ }^{\mathrm{a}}$ Corinne Boudon, ${ }^{\mathrm{a}}$ Vasilica Badets, ${ }^{\mathrm{a}}$ Antoine \\ Bonnefont, ${ }^{\mathrm{a}}$ and Laurent Ruhlmann, ${ }^{\mathrm{a}}$ \\ ${ }^{a}$ Université de Strasbourg, Institut de Chimie, UMR CNRS 7177, 4 rue Blaise Pascal, CS \\ 90032, 67081 Strasbourg cedex, France. E-mail: lruhlmann@unistra.fr \\ b Nikolaev Institute of Inorganic Chemistry SB RAS, Prospect Lavrentyeva 3, 630090 \\ Novosibirsk, Russia, E-mail: caesar@niic.nsc.ru \\ ${ }^{\mathrm{c}}$ Sorbonne Universités, UPMC Univ Paris 06, Institut des NanoSciences de Paris, UMR CNRS \\ 7588, Université Paris 6, 4 place Jussieu, boîte courrier 840, F - 75252 Paris, France \\ ${ }^{\mathrm{d}}$ Université Paris Descartes, 45 rue des Saints Pères, F - 75006 Paris, France \\ * Corresponding authors. E-mail address: 1ruhlmann@unistra.fr (L. Ruhlmann)
}

Keywords: electropolymerization · organic-inorganic hybrid composites $\cdot$ molybdenum(II) halide cluster $\cdot$ porphyrinoids $\cdot$ isoporphyrin $\cdot$ thin films $\cdot$ photocurrent generation

\begin{abstract}
:
Herein, the first example of formation of a 3D hybrid organic-inorganic copolymer based on an isoporphyrin and on a pyridine end-decorated molybdenum(II) halide cluster. The isoporphyrin copolymer thin film was obtained by electropolymerization of zinc-5,15-bis(p-tolyl)porphyrin. Electrogenerated porphyrin radical cation is a powerful electrophile which can rapidly react with the pyridine end-decorated $\mathrm{Mo}(\mathrm{II})$ halide cluster $\left(\left(\mathrm{Bu}_{4} \mathrm{~N}\right)_{2}\left[\left\{\mathrm{Mo}_{6} \mathrm{I}_{8}\right\}\left(\mathrm{OOC}-\mathrm{C}_{5} \mathrm{H}_{4} \mathrm{~N}\right)_{6}\right]\right)$ as nucleophile to form 3D copolymer containing stable isoporphyrin.

The electropolymerization of the copolymer was monitored by electrochemical quartz crystal microbalance (EQCM). The copolymer was characterized by UV-Vis-NIR spectroscopy, X-ray photoelectron spectroscopy (XPS), electrochemistry, electron spin resonance (ESR) and atomic force microscopy (AFM). The electrical properties have been studied by electrochemical impedance spectroscopy and the photovoltaic performances have been investigated by photocurrent transient measurements under visible-NIR light irradiation.
\end{abstract}




\section{Introduction}

The combination of organic and inorganic building blocks in hybrid systems often outcomes in synergism of characteristic properties. Inorganic part can be polyoxometalate which are a structurally diverse family of anionic metal-oxygen cluster anions constituted of metal elements in their highest oxidation states finding applications in analytical chemistry, medicine, homogeneous and heterogeneous catalysis, electronics and materials science [1].

Other type of cluster can be chosen as the inorganic part such as the pyridine end-decorated $\mathrm{Mo}(\mathrm{II})$ halide cluster $\left(\left(\mathrm{Bu}_{4} \mathrm{~N}\right)_{2}\left[\left\{\mathrm{Mo}_{6} \mathrm{I}_{8}\right\}\left(\mathrm{OOC}-\mathrm{C}_{5} \mathrm{H}_{4} \mathrm{~N}\right)_{6}\right]\right)$, possessing remarkable photophysical properties [2].

In this octahedral halide cluster of molybdenum(II) with the general formula $\left[\left\{\mathrm{Mo}_{6}\left(\mu_{3}-\mathrm{X}\right)_{8}\right\} \mathrm{L}_{6}\right]^{\mathrm{n}}$ $\left(\mathrm{X}=\mathrm{Cl}^{-}, \mathrm{Br}-\mathrm{I}^{-} ; \mathrm{L}=\right.$ inorganic or organic ligands; $\left\{\mathrm{Mo}_{6}\left(\mu_{3}-\mathrm{X}\right)_{8}\right\}^{4+}$ is the cluster core), the metal atom is associated with eight strongly bonded inner ligands $\mathrm{X}$ and six labile apical ligands L. Under excitation from the UV light to the green spectral regions, the clusters exhibit a broad red-NIR luminescence both in solution and solid phases. Cluster of the type $\left\{\mathrm{Mo}_{6} \mathrm{X}_{8}\right\}^{4+}(\mathrm{X}=\mathrm{Cl}$, $\mathrm{Br}$, I) with L being O-donor, N-donor, C-, P-, and S-donor ligands have been reported [2-10]. The hybrid systems formed by the supramolecular interaction constructed via metal-ligand coordination of pyridine end-decorated Mo(II) halide (X=I, polyiodometalate PIM) clusters and porphyrin have been also reported by Sokolov group. However, large excess porphyrin was taken in order to be able to have six coordinated zinc porphyrins. Indeed, this excess is needed to induce coordination due to the steric hindrance as well as the low formation constant between the pyridine subunits of PIM(py)6 and the zinc porphyrin.

To expand the practical applications of this type of cluster, their association to a visiblelight photosensitizer is still a prerequisite. Because of better ability due to better capacity for development and use, covalent cluster-porphyrin polymers would be better suited for building functional devices with photovoltaic properties.

Moreover, our group has taken advantage of the reactivity of oxidized porphyrins to develop an easy and original method of porphyrin electropolymerization. Despite the fact that 
the formation of radical cation was sufficient to perform mono-substitutions such as the formation of the monosubstituted 5 -ZnOEP-(meso-bpy) ${ }^{+}$porphyrin (bpy $=4,4^{\prime}$ '-bipyridine) when using ZnOEP (zinc- $\beta$-octaethylporphyrin), the electropolymerization failure can be attributed to the presence of the bulky ethyl groups influencing the reaction kinetics. Without a doubt, the nucleophilic attack on the $\pi$-radical cation is slower than the attack on the dication in the case of zinc- $\beta$-octaethylporphyrin (ZnOEP). Accordingly, if the characteristic time of the potential scan during the electropolymerization is shorter than that of the nucleophilic attacks onto the p-radical cation porphyrin, the substitution will not occur and the radical cation will be reduced during the cathodic scan. $A n E_{1}\left(E_{2} C_{N m e s o} E_{3} C_{B}\right)_{n}$ mechanism has been proposed in the case of 5-ZnOEP(meso-bpy) ${ }^{+}$porphyrin where the double-oxidation step at the beginning (steps $\left.E_{1} E_{2 n}\right)$ allows the electro-generation of the dication porphyrin and then the copolymer formation [11-12].

In line with this strategy, we have reported a straightforward and efficient electropolymerization procedure [13] leading to mixed porphyrin-POM copolymer films, involving either Anderson, Dawson or Lindquist type of POMs, with remarkable photoelectrocatalytic properties under visible light illumination [14]. One noteworthy characteristic of POMs is their ability to act as electron transfer relay, which can promote the transport of photo-generated electrons, avoiding the hole-electron recombination, and subsequently improve the photoelectric conversion efficiency. POMs can be used for constructing hybrids inorganic-organic systems, in which the organic dyes act as the electron donors and the POMs act as electron acceptors. It combines the advantages of the high stability of POM clusters with good finely-controllable structure of the organic subunit [15-16]. In this case, the associated POM-cation copolymer of porphyrin could be prepared by exchanging the $\mathrm{PF}_{6}{ }^{-}$counter ions with Keggin type polyoxometalate [17]. Such porphyrin-POM electrostatic assemblies could potentially be involved in photoinduced electron transfers from the porphyrin antenna (donor of electron) to the viologen or pyridinium spacers and to the POM (acceptors of electron). These materials are thus promising for the development of photoelectric devices where the type of POMs can be modulated easily. Even though the outcomes or efficiencies of these hybrid materials have not reached yet a sufficient level, the original designs and innovative synthesis route are still more than inspiring.

Furthermore, our group has shown that $\pi$-radical cation porphyrins are powerful electrophiles which can rapidly react with nucleophiles to form isoporphyrin intermediates [18]. Most isoporphyrins reported until now show a high tendency to decompose either by ring 
opening or by rearomatization to regenerate the initial porphyrin. In the case of $\beta$-octaethyl porphyrins, the corresponding isoporphyrins are not stable, due to the loss of a proton from the saturated meso-carbon atom whereas in the case of tetraphenylporphyrin (TPP), the corresponding isoporphyrin is reasonably more stable due to the substitution of the meso-carbon atoms by a phenyl group [19-20].

Recently, our new strategy led to the formation of stable isoporphyrins integrated in the copolymers. Our group has shown that stable isoporphyrins copolymers could be obtained during porphyrin electro-oxidation when sterically less hindered porphyrin is used, such as the zinc-meso-5,15-ditolyl-porphyrin $\left(\mathbf{Z n}_{\mathbf{n}} \mathbf{P}\right)$ which presents only two meso positions occupied by one substitutable proton at positions C10 and C20 (Scheme S1). This was performed in the presence of dipyridyl ligand 1,1"-(1,3-propanediyl)bis-4,4'-bipyridinium hexaflurophosphate salt ((bpy- $\left.\left(\mathrm{CH}_{2}\right)_{3}-\mathrm{bpy}^{+} 2 \mathrm{PF}^{-}\right)$. The existence of the $\pi$-cation radical of the isoporphyrin was proved by electron spin resonance spectroscopy. Further oxidation of such copolymer at higher applied potential forms a porphyrin containing copolymer with double viologen spacers, namely poly-Zn T $\mathbf{T}_{2} \mathbf{i s o P}^{\bullet}-\mathbf{b p y}^{2+}-\left(\mathbf{C H}_{2}\right)_{3}-\mathbf{b p y}^{2+}$ (top of Figure 6) [21].

In this work, the electropolymerization of a 3D hybrid copolymer material is achieved by oxidation of porphyrin such as zinc-5,15- ditolyl-porphyrin $\left(\mathbf{Z n} \mathbf{T}_{2} \mathbf{P}\right)$ as organic part in the presence of a pyridine end-decorated molybdenum(II) halide cluster $\left(\left(\mathrm{Bu}_{4} \mathrm{~N}\right)_{2}\left[\left\{\mathrm{Mo}_{6} \mathrm{I}_{8}\right\}(\mathrm{OOC}-\right.\right.$ $\left.\left.\mathrm{C}_{5} \mathrm{H}_{4} \mathrm{~N}\right)_{6}\right]$ ) (PIM(py)6) as inorganic part. Such a combination is very inviting because molybdenum(II) clusters also possess remarkable photophysical properties.

The formation of these copolymers on ITO electrode has been monitored in-situ by Electrochemical Quartz Microbalance (EQCM). The copolymer was also characterized UVVis-NIR spectroscopy, X-ray photoelectron spectroscopy, electrochemistry, ESR (Electron Spin Resonance), AFM and electrochemical impedance spectroscopy (EIS). The photocurrent generation has been investigated under visible-NIR or only NIR light illumination.

The electrochemical impedance spectroscopy properties and the photovoltaic performance of this new 3D hybrid copolymer will be compared with 1D copolymer (poly-Zn $\mathbf{T}_{2} \mathbf{i s o P}^{\bullet}-\mathbf{b p y}^{2+}{ }_{-}$ $\left.\left(\mathrm{CH}_{2}\right)_{3}-\mathrm{bpy}^{2+}\right)$. 


\section{Experimental}

\subsection{Reagents and apparatus}

All solvents were of reagent grade quality and used without further purification.

The free base 5,15-bis(p-tolyl)porphyrin $\left(\mathrm{H}_{2} \mathrm{~T}_{2} \mathrm{P}\right)$ [22-24] was synthetized according to published procedures from 2,20-dipyrromethane and p-tolualdehyde [25]. The free base was then metallated with $\mathrm{Zn}(\mathrm{OAc})_{2}$ in THF to give zinc-5,15-bis(p-tolyl)porphyrin $\left(\mathbf{Z n T}_{2} \mathbf{P}\right)$.

The pyridine end-decorated molybdenum(II) halide cluster PIM(py)6 (Figure S1) was synthetized according to published procedures [2].

Voltammetric data have been recorded with a standard three-electrode system using a PARSTAT 2273 potentiostat. The electrolyte was $\mathrm{CH}_{3} \mathrm{CN} / 1,2-\mathrm{C}_{2} \mathrm{H}_{4} \mathrm{Cl}_{2}$ (3/7) containing $0.1 \mathrm{~mol}$ $\mathrm{L}^{-1}$ of tetrabutylammonium hexafluorophosphate $\left(\mathrm{NBu}_{4} \mathrm{PF}_{6}\right)$. Single-side coated indium-tinoxide (ITO, SOLEMS, 25-35 $\Omega / \mathrm{cm}^{2}$ ) electrodes with a surface area of $1 \mathrm{~cm}^{2}$ were used as working electrode, and a platinum wire as auxiliary electrode. The reference electrode was the saturated calomel electrode which was electrically connected to the solution by a junction bridge filled with electrolyte. The electrochemical impedance spectrum (EIS) measurements were carried out at sinusoidal voltage excitation with amplitude of $10 \mathrm{mV}$ in a frequency range from $100 \mathrm{kHz}$ to $100 \mathrm{mHz}$. The ITO electrodes were also used to obtain UV-vis spectra of the electrochemically deposited copolymers on an Agilent 8453 spectrophotometer.

A QCA-922 (SEIKO EG\&G instrument) system combined with Versa STAT 3 was used for simultaneous electrochemical quartz crystal measurement (EQCM) and cyclic voltammetric measurements. The electrochemical cell was assembled in a glove box using an ITO AT-cut quartz crystal resonator (mirror finished, resonant frequency: $9.08 \mathrm{MHz} \pm 50 \mathrm{kHz}, \mathrm{A}=0.2 \mathrm{~cm}^{2}$, SEIKO EG\&G., LTD) as working electrode, a platinum wire as counter electrode, and a $\mathrm{Ag} / \mathrm{AgCl}$ wire as a quasi-reference electrode. The solution used for the electropolymerization here is the same as the one we used for electropolymerization of the copolymers with the larger ITO electrode. Iterative scans were conducted at a scan rate of $100 \mathrm{mV} \cdot \mathrm{s}^{-1}$ at room temperature with simultaneous recording of the quartz resonance frequency. The change of the quartz resonance frequency $(\Delta \mathrm{f})$ was converted into the mass change $(\Delta \mathrm{m})$ on the ITO-coated quartz during iterative cycling by applying Sauerbrey's equation (eq 1):

$$
\Delta \mathrm{f}=-2 \mathrm{f}_{0}{ }^{2} \Delta \mathrm{m} / \mathrm{A}(\mu . \rho)^{1 / 2}
$$

where $f_{0}$ is the resonant frequency of the fundamental mode, $\rho$ is density of the crystal $(2.684$ $\left.\mathrm{g} / \mathrm{cm}^{3}\right)$, A is working area $\left(0.2 \mathrm{~cm}^{2}\right)$ of the ITO quartz crystal resonator, $\mu$ is shear modulus of 
quartz $\left(2.947 \times 10^{11} \mathrm{~g} \cdot \mathrm{cm}^{-1} \cdot \mathrm{s}^{-2}\right)$.

XPS experiments were carried out on a RBD upgraded PHI-5000C ESCA system (PerkinElmer) with MgKR radiation $(h=1253.6 \mathrm{eV})$ or Al KR radiation $(h=1486.6 \mathrm{eV})$. In general, the $\mathrm{X}$-ray anode was run at $250 \mathrm{~W}$ and the high voltage was kept at $14.0 \mathrm{kV}$ with a detection angle at $54^{\circ}$. The pass energy was fixed at $23.5,46.95$, or $93.90 \mathrm{eV}$ to ensure sufficient resolution and sensitivity. The base pressure of the analyzer chamber was about $5 \times 10^{-8} \mathrm{~Pa}$. The sample was directly pressed to a self-supported disk $(10 \mathrm{x} 10 \mathrm{~mm})$ and mounted on a sample holder then transferred into the analyzer chamber. The whole spectra $(0-1100 \mathrm{eV})$ and the narrow spectra of all the elements with higher resolution were both recorded by using RBD 147 interface (RBD Enterprises, U.S.A.) through the Auger Scan 3.21 software. Binding energies were calibrated by using the containment carbon $(\mathrm{C} 1 \mathrm{~s}=284.6 \mathrm{eV})$. The data analysis was carried out by using the RBD Auger Scan 3.21 software provided by RBD Enterprises or XPS Peak 4.1 provided by Raymund W.M. Kwok (The Chinese University of Hongkong, China).

Atomic force micrographs (AFM) measurements have been conducted directly on the ITO surfaces using a Dimension 3100 (Veeco) in the tapping mode under ambient conditions. Silicon cantilevers (Veeco probes) with a spring constant of $300 \mathrm{~N} / \mathrm{m}$ and a resonance frequency in the range of $120-139 \mathrm{kHz}$ have been used. The scanning rate was $1.0 \mathrm{~Hz}$.

Photoelectrochemical measurements were performed in a three-electrode electrochemical cell using glass-ITO electrodes covered by the copolymer thin film as photocathode, Pt plate as counter-electrode and $\mathrm{Pt}$ wire as pseudo-reference electrode. The photoelectrochemical responses of the copolymer were obtained by on-off light illumination in $5 \mathrm{mM} \mathrm{I}_{3}^{-} / 0.5 \mathrm{M} \mathrm{I}^{-}$ aqueous solution using a $300 \mathrm{~W}$ Xe arc lamp. $\mathrm{I}_{3}{ }^{-}$and $\mathrm{I}^{-}$anions act as redox mediator. The scheme of the experimental set-up can be found in Scheme S3. Water filter was used to avoid IR radiation and long pass filters either at $\lambda>385 \mathrm{~nm}$ or $\lambda>800 \mathrm{~nm}$ were used to keep only visible-NIR or NIR radiations, respectively. Current-potential curves measurements were recorded in the dark and under illumination with PARSTAT 2273 potentiostat using linear sweep voltammetry at $10 \mathrm{mV} \mathrm{s}^{-1}$. EIS spectra were obtained under illumination by applying sinusoidal modulation of the potential $(10 \mathrm{mV}$ over the Open Circuit Photopotential) at frequencies from $10^{-1}$ to $10^{5} \mathrm{~Hz}$.

\section{Results and Discussion}

\subsection{Redox and optical properties of pyridine end-decorated molybdenum(II) halide}




\section{cluster PIM(py)6}

The electrochemical behaviour of $\left(\mathrm{Bu}_{4} \mathrm{~N}\right)_{2}\left[\mathrm{Mo}_{6} \mathrm{I}_{8}(\mathrm{COOpy})_{6}\right]$ (PIM(py)6 (Figure 1A) has been studied by cyclic voltammetry. Three different working electrodes have been used to study PIM(py)6 in solution: a glassy carbon electrode ( $\mathrm{GC}, \mathrm{d}=3 \mathrm{~mm}, \mathrm{~A}=0.283 \mathrm{~cm}^{2}$ ), a platinum electrode $\left(\mathrm{Pt}, \mathrm{A}=1.0 \mathrm{~cm}^{2}\right)$ and an indium tin oxides electrode (ITO, $\left.\mathrm{A}=1.0 \mathrm{~cm}^{2}\right)$.

$\operatorname{PIM}(\mathbf{p y}) \mathbf{6}^{2-}$ showed similar redox behaviour on GC and Pt electrodes as shown in Figure 1 and Figure S1 respectively. One reversible oxidation appeared near $1.32 \mathrm{~V}$. The $I_{p a} / I_{p c}$ is close to 1 and it was assumed to be the oxidation of $\left\{\mathrm{Mo}_{6} \mathrm{I}_{8}\right\}^{4+} /\left\{\mathrm{Mo}_{6} \mathrm{I}_{8}\right\}^{5+}$ according to the literature [26]. The small pre-peak (a) observed in Figure 1C is due to the adsorption of PIM(py)6 on the Pt electrode. It corresponds to the oxidation of the adsorbed PIM(py)6. In the case of Pt electrode for instance, the peak current a increase linearly with the scan rate $v$, as shown in Figure 1D, which indicates that this wave is not controlled by the diffusion. It proves that this peak corresponds to the oxidation of the absorbed PIM(py)6. In contrast, $\mathrm{I}_{\mathrm{pa}}$ or $\mathrm{I}_{\mathrm{pc}}$ (anodic or cathodic peak current) of wave I increases linearly with the square root of the scan rate showing that wave I corresponds to the diffusion-controlled redox process.

However, in the case of ITO electrode, the anodic peak current $\mathrm{I}_{\mathrm{pa}}$ is always higher than the cathodic peak current $\mathrm{I}_{\mathrm{pc}}$, that means the cluster $\left\{\mathrm{Mo}_{6} \mathrm{I}_{8}\right\}^{5+}$ is not reduced completely on the reverse sweep as shown in Figure S1B. The potential of the oxidation corresponding of the step I is also measured at lower potential (i.e. $1.09 \mathrm{~V}$ ). It may be due to the absorption of the oxidized compound on the surface of the ITO electrode. In this case, it must be noticed that additional reduction peak is observed at $-0.96 \mathrm{~V}$ (peak $*$ ) in the cathodic domain. This additional peak may be due to the irreversible reduction of the adsorbed compound.

When a higher potential was reached in the anodic domain in the case of GC electrode as shown in Figure 1E, one additional irreversible peak II is observed at $1.96 \mathrm{~V}$. It may be due to the decomposition of the cluster core due to the fully oxidation of the starting Mo ${ }^{\mathrm{II}}$ atoms [27-29]. Moreover, one irreversible peak (peak III) is also observed at $-1.57 \mathrm{~V}$ and corresponds to the irreversible reduction of $\left\{\mathrm{Mo}_{6} \mathrm{I}_{8}\right\}^{4+} /\left\{\mathrm{Mo}_{6} \mathrm{I}_{8}\right\}^{3+}$ (Figure 1F). 

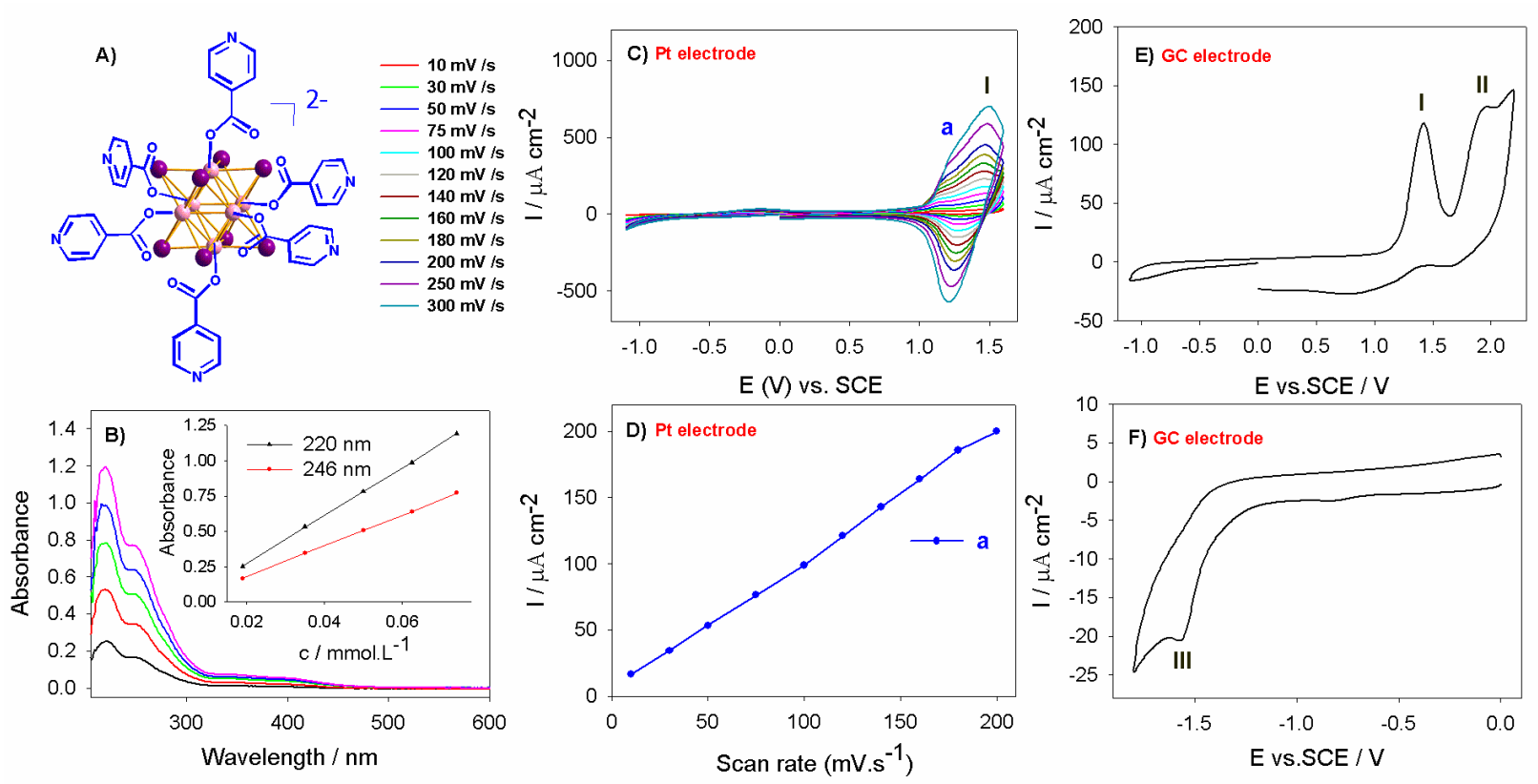

Figure 1 A) Structures of $\left[\mathrm{Mo}_{6} \mathrm{I}_{8}(\text { pyCOO })_{6}\right]^{2-}$ (PIM(py)6). B) UV-vis spectra of PIM(py)6 with different concentration in 7/3 1,2-dichloroethane / acetonitrile. C) Cyclic voltammograms of $\operatorname{PIM}(\mathbf{p y})_{6}\left(0.25 \mathrm{mmol} \mathrm{L}^{-1}\right)$ recorded between $-1.1 \mathrm{~V}$ and $+1.6 \mathrm{~V} v s$. SCE on Pt electrode with increasing scan rate in a $1,2-\mathrm{C}_{2} \mathrm{H}_{4} \mathrm{Cl}_{2} / \mathrm{CH}_{3} \mathrm{CN}(7 / 3)$ solution in the presence of $\mathrm{NBu}_{4} \mathrm{PF}_{6}(0.1$ mol L $\left.{ }^{-1}\right)$. D) Peak "a" current versus the scan rate. E) and F) Cyclic voltammograms of cluster complexes of PIM(py)6 in $7 / 3$ 1,2-EtCl $/ \mathrm{CH}_{3} \mathrm{CN}$ solution in the presence of $\mathrm{NBu}_{4} \mathrm{PF}_{6}(0.1 \mathrm{~mol}$ $\left.\mathrm{L}^{-1}\right)$ on glassy carbon electrode $(\mathrm{d}=3 \mathrm{~mm})(\mathrm{A})-1.1 \mathrm{~V}$ to $2.2 \mathrm{~V}(\mathrm{~B}) 0.0 \mathrm{~V}$ to $-1.8 \mathrm{~V} . v=100 \mathrm{mV}$ $\mathrm{s}^{-1}$.

The optical spectrum of PIM(py) $)_{6}$ is presented in Figure 1B. With the increase of concentration of PIM(py)6, the absorption intensity also increases as expected from the Beer-Lambert law. The absorption bands in UV region is due to the $\pi-\pi^{*}$ transitions in the aromatic terminal ligands. The broad and featureless absorption wavelength longer than $350 \mathrm{~nm}$ may due to the $\left\{\mathrm{Mo}_{6} \mathrm{I}_{8}\right\}^{4+}$ core-centered $\mathrm{d}-\mathrm{d}$ transitions [7]. The result is consistent with the data reported in the literature [7-3031]. The energy gap calculated from optical spectrum at $402 \mathrm{~nm}(3.08 \mathrm{eV})$ between HOMO and LUMO orbitals is close to the value calculated from the electrochemistry: $2.89 \mathrm{eV}$ on GC electrode $\left(\mathrm{E}_{\mathrm{ox}}-\mathrm{E}_{\mathrm{red}}=1.32-(-1.57)=2.89 \mathrm{eV}\right)$.

\subsection{Formation of 3D electropolymerized thin film based on a isoporphyrin and on a pyridine end-decorated molybdenum(II) halide cluster}

The molecular precursors porphyrins zinc-5,15-bis(p-tolyl)porphyrin $\left(\mathbf{Z n T}_{\mathbf{2}} \mathbf{P}\right)$, as well as the pyridine end-decorated $\mathrm{Mo}(\mathrm{II})$ halide cluster $\left(\left(\mathrm{Bu}_{4} \mathrm{~N}\right)_{2}\left[\left\{\mathrm{Mo}_{6} \mathrm{I}_{8}\right\}\left(\mathrm{OOC}-\mathrm{C}_{5} \mathrm{H}_{4} \mathrm{~N}\right)_{6}\right]\right)$ (PIM(py)6) are depicted in Scheme S1. The syntheses of the isoporphyrin copolymer was achieved via our previously reported electropolymerization method [21]. It relies on the addition of hexapyridyl 
ligand to an electro-generated $\pi$-radical cation porphyrin produced by iterative voltammetric scans (Scheme 1). The electrosyntheses of the (iso)porphyrin copolymers poly-Zn $\mathbf{T}_{2} \mathbf{i s o P} \mathbf{P}^{\bullet}$ $\operatorname{PIM}\left(\mathbf{p y}^{+}\right)_{6}$ requires the attack of a pyridyl ligand to an electro-generated $\pi$-radical cation porphyrin produced by oxidation. Thus, the pyridine end-decorated molybdenum halide cluster (PIM(py)6) can combine with $\mathbf{Z n T}_{2} \mathbf{P}$ porphyrin through the pendant pyridyl ligands in order to form pyridinium linkers between porphyrin macrocycles. The zinc-meso-5,15ditolylporphyrin $\left(\mathbf{Z n T}_{2} \mathbf{P}\right)$ presents only two meso positions occupied by one substitutable proton at positions $\mathrm{C} 10$ and $\mathrm{C} 20$. Additionally, all the $\beta$ positions of $\mathbf{Z n T}_{2} \mathbf{P}$ are occupied only by protons. Such porphyrin will provide better accessibility for the PIM(py)6 (Scheme 1). Electrosynthesis of $\mathrm{Zn}$ and $\mathrm{Mg}$ meso-triarylphosphonium porphyrin were as well reported from $\mathrm{Zn}$ or $\mathrm{Mg}$ 5,10,15-triarylporphyrin indicating a nucleophilic substitution is mainly at the meso and not at the $\beta$ position [32]. Furthermore, the electrochemical oxidation of pyridin-2-ylthiomeso substituted Ni(II) porphyrins afforded oxidative C-N fusion of pyridinylsubstituted porphyrins again at the meso position giving cationic and dicationic pyridinium-based products [33].

As already reported, for zinc 5,15-ditolyl porphyrin $\left(\mathbf{Z n}_{\mathbf{n}} \mathbf{P}\right)$, the nucleophilic attack appears to be allowed only at the 10 as well as the 20 meso positions of the porphyrin [21]. It should also be noted that in the absence of nucleophile, the electrogenerated radical $\mathbf{Z n T}_{2} \mathbf{P}^{+\bullet}$ may undergo a radical coupling reaction and the formation of one dimer with $\mathrm{C}-\mathrm{C}$ bond formation through meso-meso, meso- $\beta$ or $\beta-\beta$ link between two porphyrins. Actually, previous works in the literature using the 5,15-bis(3,5-di-tert-butylphenyl) porphyrin presented only the formation of a mixture of meso-meso and meso- $\beta$ linked dimers. These dimers showed a splitting of the Soret band of the optical spectra [34-36].

However, when potential iterative scans are performed between $0.9 \mathrm{~V}$ and $-1.1 \mathrm{~V} v s$. SCE using $\mathbf{Z n T}_{2} \mathbf{P}$ alone (in the absence of PIM(py)6) an absence of deposit or the formation of a film is observed onto the ITO electrode signifying that the kinetic of radical coupling reaction is relatively slow. It must be noted that the formation of dimer and eventually small oligomer which are soluble cannot be completely excluded. However, no change of the optical spectrum of the solution was observed.

During the oxidation of $\mathbf{Z n T}_{2} \mathbf{P}$ in the presence of PIM(py) $\mathbf{P}$ between $-1.1 \mathrm{~V}$ and $+0.9 \mathrm{~V} v s$. SCE (just after the first porphyrin-based oxidation potential), the $\pi$-radical cation $\mathbf{Z n T} \mathbf{T}_{2} \mathbf{P}^{+\bullet}$ is produced when reaching $+0.9 \mathrm{~V}$. It must be noted that at applied potential of $+0.9 \mathrm{~V}$, the reversible oxidation of PIM(py)6 not yet occurs because the oxidation potential is $1.09 \mathrm{~V} v s$. SCE. Significant changes of the cyclic voltammogram are observed during iterative scans of 
the electropolymerization process. As shown in Figure 2A, in the anodic part, the intensity of the oxidation peak corresponding to the first oxidation of the porphyrin $Z_{n} \mathbf{T}_{2} \mathbf{P}$ continuously increased during the electropolymerization which is correlated to the increase of the film thickness. This also shows the formation of $\mathbf{p o l y}-\mathbf{Z n T}_{2} \mathbf{i s o P}^{\bullet}-\mathbf{P I M}\left(\mathbf{p y}^{+}\right)_{6}$ copolymer.

The first scan toward negative potentials presents no signal. Starting with the second scan, in the cathodic potential range, the quasi-reversible reduction wave appeared near $-1.0 \mathrm{~V} v s$. SCE (Figure 2A) has been attributed to the reduction on the electrogenerated pyridinium units introduced between two porphyrins. The continuous increase of these reduction waves indicates a regular growth of the copolymer film onto the ITO working electrode.

It should be noted that when the iterative scan is conducted between $-1.1 \mathrm{~V}$ and $1.6 \mathrm{~V}$, a partial decomposition of the film is observed (Figure S2B). This is probably due to the second irreversible oxidation of the PIM(py)6 cluster (Figure 1E, peak II).

The formation of poly-Zn $\mathbf{T}_{2} \mathbf{i s o P}^{\bullet}$-PIM $\left(\mathbf{p y}^{+}\right)_{6}$ by electropolymerization with iterative scans between -1.1 and $+0.9 \mathrm{~V}$ has been also monitored in-situ by EQCM (Figure 2B).

Besides, the trace of the first scan in Figure 2B shows a significant decrease of the resonance frequency and thus an increase of the deposited mass at the first oxidation of the porphyrin; i.e. electropolymerization occurs upon the formation of the radical cation porphyrin $Z_{n} \mathbf{T}_{2} \mathbf{P}^{+\bullet}$ in the presence of PIM(py)6.

The resonance frequency displays a significant decrease meaning an increase of the deposited mass during the electropolymerization as shown in Figure $2 \mathrm{~B}$. The mass of the copolymer film increases with the number of iterative scan n (Figure 2C).

Note that a change of slope is observed for $n>12$. It might be related to a transition of the pure $3 \mathrm{D}$ architecture of the copolymer film to the copolymer with defects and with the incorporation of supporting electrolyte, monomers as well as solvent molecules.

Assuming that the repeat unit is $\left[3 \mathrm{ZnT}_{2} \mathrm{P}_{-} \mathrm{PIM}^{2-}\left(\mathrm{py}^{+}\right)_{6}\right] 2 \mathrm{TBA}^{+} \cdot 6 \mathrm{PF}_{6}^{-}$in the case of the pure $3 \mathrm{D}$ material, the calculated surface coverage $\Gamma$ is $1.74 \times 10^{-10}$ mol.cm $\mathrm{cm}^{-2}$ after only one scan between $-1.1 \mathrm{~V}$ and $+0.9 \mathrm{~V}$. The theoretical values of mass change can be calculated and are given in Table S1 in the case of the formation of 1D or 3D copolymer.

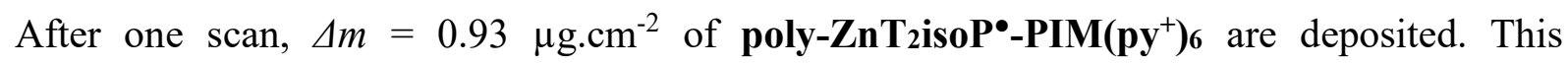
experimental value is close to the theoretical mass deposited (i.e. $1.06 \mu \mathrm{g} . \mathrm{cm}^{-2}$ ) calculated by using the anodic charge $\left(\mathrm{Q}=1.73 .10^{-4} \mathrm{C}\right)$ as well as the molecular mass matching to the $3 \mathrm{D}$ copolymer (5337.2 g.mol ${ }^{-1}$ ). Furthermore, it is more distant to the value obtained in the case of the $1 \mathrm{D}$ copolymer (i.e. $2.18 \mu \mathrm{g} . \mathrm{cm}^{-2}$ ). These results may suggest the formation of the $3 \mathrm{D}$ 
copolymer. The yield of the formation of the such copolymer can be estimated and is given in Table S2. The calculated yield is $88 \%$ for $\mathrm{n}=1$ and it decreases with the number of iterative scans giving $39 \%$ for $n=25$ scans. This can be correlated to the increase of the resistance when the thickness of the film increases.

By the integration of the pyridinium reduction wave, the value of $\Delta m_{\text {calc }}=2.15 \mu \mathrm{g} \cdot \mathrm{cm}^{-2}$ of copolymer deposited is calculated after 3 iterative scans assuming that a $3 \mathrm{D}$ copolymer is formed. This reduction corresponds to the 6 electrons process per copolymer unit. The value is in reasonable agreement with the measured value which is $2.79 \mu \mathrm{g} . \mathrm{cm}^{-2}$ (Table S2).

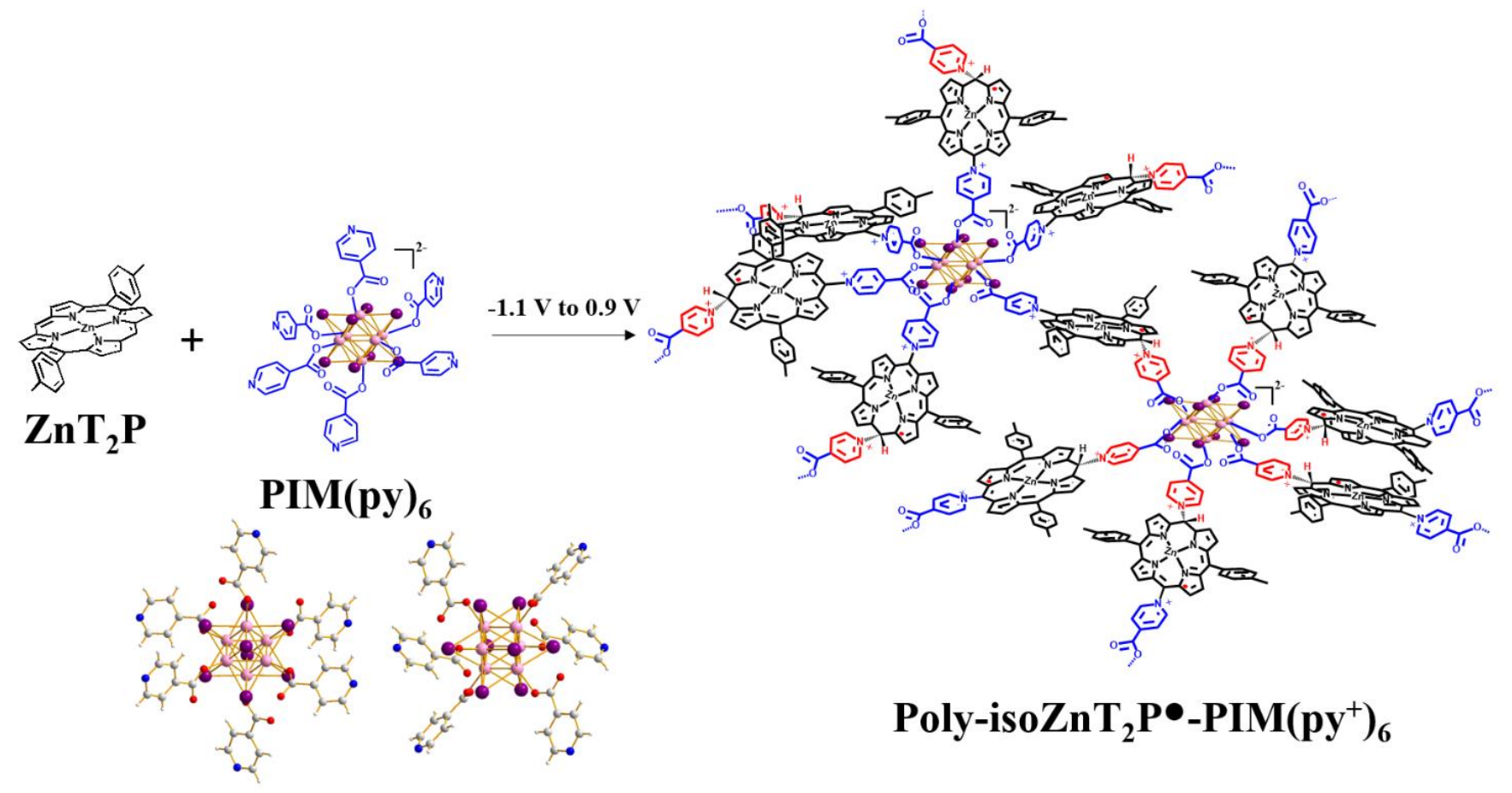

Scheme 1. The electropolymerization process of poly-ZnT $\mathbf{T}_{2} \mathbf{i s o P}^{\bullet}-\mathbf{P I M}\left(\mathbf{p y}^{+}\right)_{6}$. 

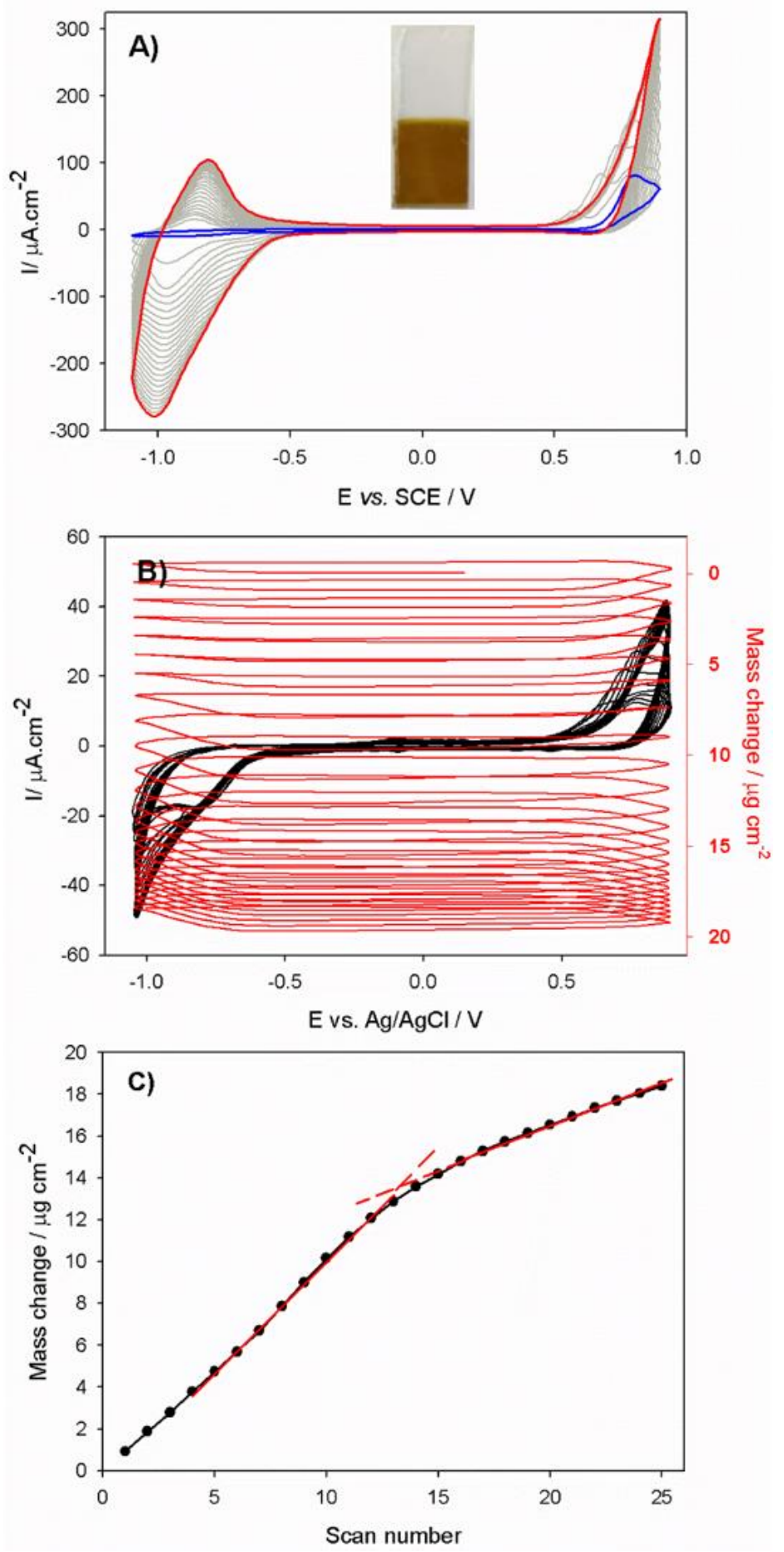

Figure 2. A) Cyclic voltammograms recorded during 25 iterative scans conducted between $-1.1 \mathrm{~V}$ and +0.9 $\mathrm{V} / \mathrm{SCE}$ and B) $-1.1 \mathrm{~V}$ and $+1.6 \mathrm{~V} v \mathrm{~s}$. SCE in a $1,2-\mathrm{C}_{2} \mathrm{H}_{4} \mathrm{Cl}_{2} / \mathrm{CH}_{3} \mathrm{CN}(7 / 3)$ solution of $\mathbf{Z n} \mathbf{T}_{2} \mathbf{P}\left(0.25 \mathrm{mmol} \mathrm{L}^{-1}\right)$ in the presence of PIM(py) $)_{6}\left(0.25 \mathrm{mmol} \mathrm{L}^{-1}\right)$ and $\mathrm{NBu}_{4} \mathrm{PF}_{6}\left(0.1 \mathrm{~mol} \mathrm{~L}^{-1}\right)$. WE: ITO. $\mathrm{S}=1 \mathrm{~cm}^{2} \cdot v=100 \mathrm{mV}$ $\mathrm{s}^{-1}$. Blue curve: first scan $(n=1)$. Red curve: final scan $(n=25)$. Red curve: highest reduction current. B) Consecutive cyclic voltammograms (first 25 scans) between -1.1 and $0.9 \mathrm{~V}$ and electrochemical quartz crystal microbalance measurements $(\Delta m)$ for the first 25 scans during the formation of poly-ZnnT $\mathbf{T}_{2} \mathbf{i s o P}^{\bullet} \mathbf{- P I M}\left(\mathbf{p y} \mathbf{y}^{+}\right)_{\mathbf{6}}$ obtained by the electropolymerization of $0.25 \mathrm{mmol} \mathrm{L}^{-1} \mathbf{Z n T}_{2} \mathbf{P}$ with $0.25 \mathrm{mmol} \mathrm{L}^{-1} \mathbf{P I M}(\mathbf{p y})_{6}(0.25 \mathrm{mmol}$ $\left.\mathrm{L}^{-1}\right)$ in 1,2- $\mathrm{C}_{2} \mathrm{H}_{4} \mathrm{Cl}_{2}-\mathrm{CH}_{3} \mathrm{CN}(7 / 3)$ in the presence of $0.1 \mathrm{~mol} \mathrm{~L}^{-1} \mathrm{NBu}_{4} \mathrm{PF}_{6}$. Working electrode: ITO $(\mathrm{A}=0.2$ $\mathrm{cm}^{2}$ ) deposited on a $9.08 \mathrm{MHz}$ AT-cut quartz crystal. $v=100 \mathrm{mVs}^{-1}$. C) Mass change ( $\left.\Delta \mathrm{m}\right)$ of the first 25 scans calculated from Sauerbrey's equation versus the number of scan $\mathrm{n}$. 


\subsection{Optical properties, Electron spin resonance (ESR) spectroscopy, film Morphology}

\section{(Atomic Force Microscopy) and XPS of the 3D copolymer}
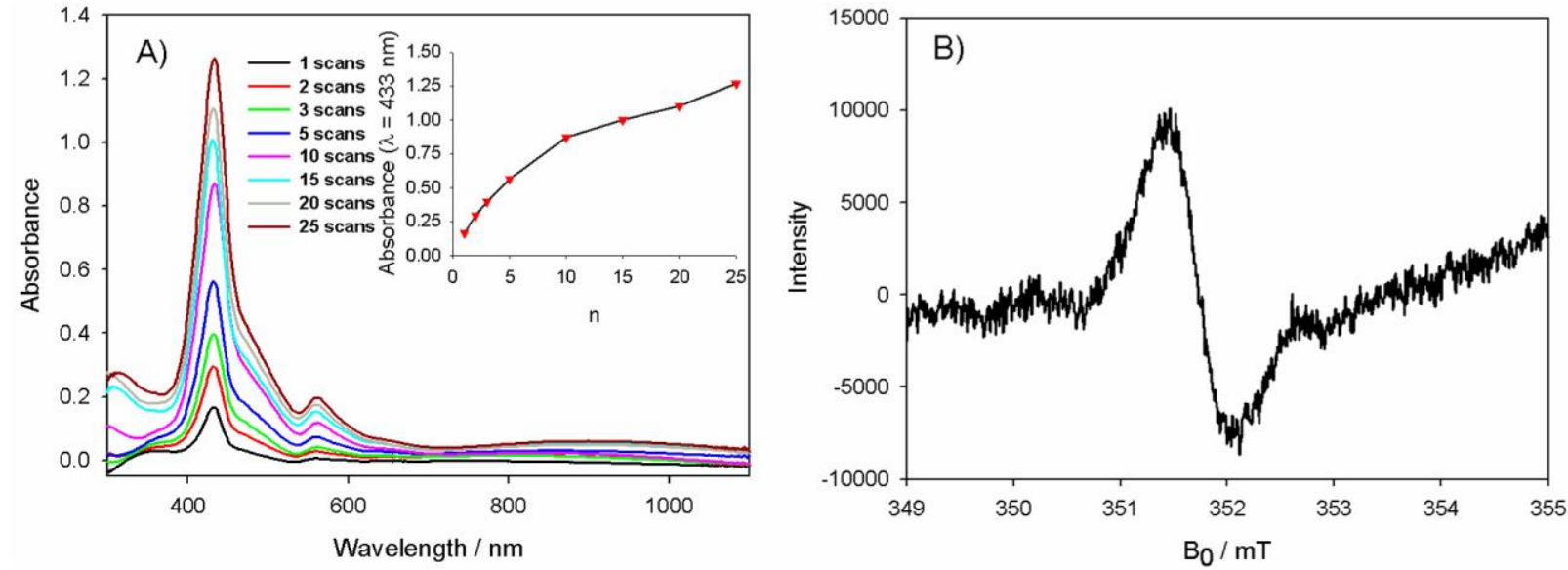

C)
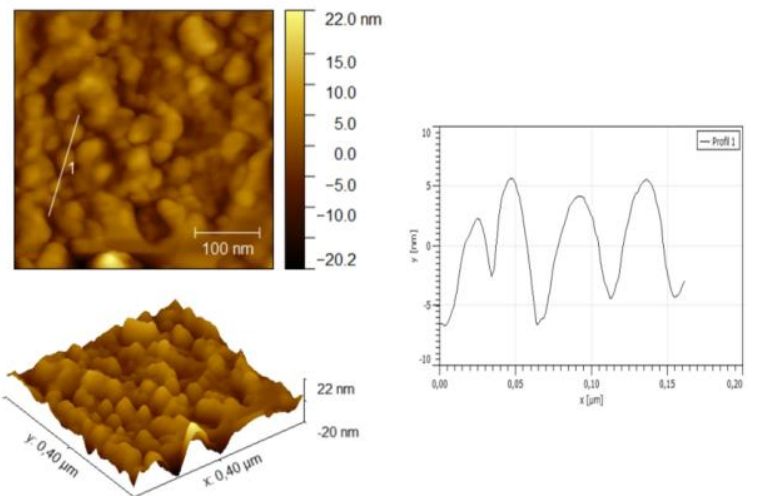

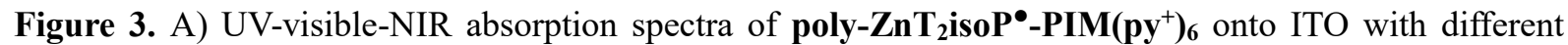
numbers of iterative scans between -1.1 and $+0.9 \mathrm{~V} v s$. SCE $\left(v=100 \mathrm{mV} \mathrm{s}^{-1}\right)$. Only one side of the slide is covered by ITO. Inset: plot of the absorbance measured at $\lambda=433 \mathrm{~nm}$ versus $\mathrm{n}$ the numbers of iterative scans. B) ESR spectrum of poly-ZnT $\mathbf{T}_{2}$ isoP ${ }^{\square}$-PIM(py $\left.{ }^{+}\right)_{6}$ in DMF at room temperature. The solution of poly$\mathbf{Z n T}_{2} \mathbf{i s o P}^{\square}$-PIM( $\left.\mathbf{p y}^{+}\right)_{6}$ was prepared by washing with $160 \mu \mathrm{L}$ of DMF three covered ITO obtained using 25 scans between $-1.1 \mathrm{~V}$ and $0.9 \mathrm{~V}, v=100 \mathrm{mV} \mathrm{s}^{-1}$. C) Left: tapping mode AFM topography of poly-Zn $\mathbf{T}_{2} \mathbf{i s o}^{\bullet} \mathbf{P}^{\bullet}$ $\operatorname{PIM}\left(\mathbf{p y}^{+}\right)_{6}($ deposition between $-1.1 \mathrm{~V}$ and $+0.9 \mathrm{~V}$ vs. SCE on ITO, $n=1$ ). Right: section analysis of the aggregate marked by a white line.

Table 1. UV-visible spectral data for $\mathbf{Z n T}_{2} \mathbf{P}$ in $\mathrm{CH}_{3} \mathrm{Cl}$, PIM(py) ${ }_{6}$, poly-ZnT $\mathbf{Z}_{2} \mathbf{i s o P}^{\bullet} \mathbf{P}^{\bullet} \mathbf{P I M}\left(\mathbf{p y}^{+}\right)_{6}$ in $1,2-\mathrm{EtCl}_{2}$, on optical transparent ITO electrodes. Under bracket: molar extinction coefficient $\left(\varepsilon / 10^{3} \mathrm{~L} .{\mathrm{M} . \mathrm{cm}^{-1}}^{-1}\right.$.

\begin{tabular}{|c|c|c|c|}
\hline Compound & Soret band/nm & Q bands/nm & $\pi-\pi^{*}$ Band $/ \mathbf{n m}$ \\
\hline $\mathrm{ZnT}_{2} \mathbf{P}$ & $415(405.4)$ & $546(18.9), 584(4.9)$ & \\
\hline $\operatorname{PIM}(p y)_{6}{ }^{a}$ & & & $\begin{array}{l}220 \quad(170.4), \quad 246 \\
(109.0), 344 \quad(11.0), \\
402(8.0)\end{array}$ \\
\hline
\end{tabular}




\begin{tabular}{|c|c|c|}
\hline poly-ZnT ${ }_{2}$ isoP $^{\bullet}$-PIM $\left(\mathrm{py}^{+}\right)_{6}{ }^{b}$ & 433,475 & $561,645,875$ \\
\hline poly-ZnT ${ }_{2}$ isoP $^{\bullet}$-PIM $\left(\text { py }^{+}\right)_{6}{ }^{c}$ & 417 & 547,644 \\
\hline poly-ZnT $_{2}$ P-PIM $\left(\mathrm{py}^{+}\right)_{6}{ }^{\mathrm{d}}$ & 434 & 567,607 \\
\hline
\end{tabular}

${ }^{a}$ in $1,2-\mathrm{EtCl}_{2} / \mathrm{CH}_{3} \mathrm{CN}(7 / 3)$.

${ }^{\mathrm{b}}$ Copolymers obtained by iterative scan between $-1.1 \mathrm{~V}$ and $+0.9 \mathrm{~V} v s$. SCE onto ITO.

${ }^{\mathrm{c}}$ Copolymers obtained by iterative scan between $-1.1 \mathrm{~V}$ and $+0.9 \mathrm{~V} v s$. SCE in DMF.

${ }^{\mathrm{d}}$ Copolymers obtained by iterative scan between $-1.1 \mathrm{~V}$ and $+1.6 \mathrm{~V} v s$. SCE onto ITO. 
UV-visible-NIR spectra on ITO electrodes coated with the copolymer poly-Zn $\mathbf{T}_{2} \mathbf{i s o}^{\bullet} \mathbf{P}^{\bullet}$ $\operatorname{PIM}\left(\mathbf{p y}^{+}\right)_{6}$ have been measured at various thickness (Figure 3A). The absorption intensity of the isoporphyrin increases linearly with iterative scan number (inset of Figure 3A).

A typical UV-visible-NIR spectrum of poly-ZnT 2 isoP•-PIM(py $\left.{ }^{+}\right)_{6}$ obtained after electropolymerization between -1.1 and $+0.9 \mathrm{~V}$ exhibited a broad split Soret absorption band at $\lambda=433 \mathrm{~nm}$ and $\lambda=475 \mathrm{~nm}$. The bands were red-shifted by 18 and $60 \mathrm{~nm}$ respectively as compared to the $\mathbf{Z n} \mathbf{T}_{2} \mathbf{P}$ monomer (Table 1). The visible bands ( $\mathrm{Q}$ bands), observed at 561 and $645 \mathrm{~nm}$, are also red-shifted by 15 and $61 \mathrm{~nm}$ compared to $\mathbf{Z n T} \mathbf{T}_{2} \mathbf{P}$ and an additional band at $875 \mathrm{~nm}$ in the NIR region is detected. These electropolymerized films have been found to be fully soluble in DMF. Analysis of poly-ZnT2isoP•-PIM( $\left.\mathbf{p y}^{+}\right)_{6}$ in solution by UV-Vis-NIR absorption spectroscopy revealed distinct spectrum than the one recorded on the solid film (Figure S3). The NIR band is not detected and the red-shift of the Soret band is lower.

The superposition of the UV-visible-NIR absorption spectra of $\mathbf{Z n} \mathbf{T}_{\mathbf{2}} \mathbf{P}$ in solution and of the

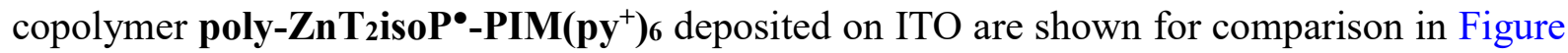
S3. It reveals that for poly-Zn $\mathbf{T}_{2} \mathbf{i s o}^{\bullet} \mathbf{P}^{\bullet}-\mathbf{P I M}\left(\mathbf{p y}^{+}\right)_{6}$ the Soret band, attributed to the isoporphyrinbased $\pi-\pi^{*}$ electronic transition, is much broader and is split with significant red-shift in the case of the film deposited onto ITO electrode compared to the starting monomer $\mathbf{Z n T}_{\mathbf{2}} \mathbf{P}$ in DMF solution (Table 1).

The red shift of the Soret (B) and the Q bands might result from the presence of the electronwithdrawing pyridinium groups as well as from the nonplanar conformation of the isoporphyrin. Optical red shifts induced by the non-planarity of the macrocycle are well documented [37-40] and have been rationalized by a larger destabilization of the highest occupied molecular orbitals (HOMOs) relative to the lowest unoccupied molecular orbitals (LUMOs) resulting in smaller HOMO to LUMO gaps [41-44].

These changes can also be understood taking into account the presence of intra- and intermolecular exciton-coupling between the porphyrin macrocycle within the copolymer [4546].

The additional bands at 475 and $875 \mathrm{~nm}$ are attributed to the isoporphyrin structure present in the copolymer as already observed. $[\mathbf{2 1 , 4 7 ]}$

Interestingly, the broadening and the splitting of the Soret band as well as the presence of one additional band in the NIR between $750 \mathrm{~nm}$ and $1000 \mathrm{~nm}$ are expected to be advantageous to photovoltaic applications by extending the domain of solar light absorption. Poly-ZnT 2 isoP•$\operatorname{PIM}\left(\mathbf{p y}^{+}\right)_{6}$ isoporphyrin radical film was found to be highly stable in the presence of oxygen (still stable even after one year). 
To confirm the presence of the organic radical, poly-Zn $\mathbf{T}_{2} \mathbf{i s o P} \mathbf{P}^{\bullet}-\mathbf{P I M}\left(\mathbf{p y}^{+}\right)_{6}$ films onto ITO were prepared (25 iterative scans between $-1.1 \mathrm{~V}$ and $0.9 \mathrm{~V}, v=100 \mathrm{mV} . \mathrm{s}^{-1}$ ). Poly-ZnT 2 isoP• $\operatorname{PIM}\left(\mathbf{p y}^{+}\right)_{6}$ was then removed from ITO using DMF and this procedure was repeated three times. The obtained solutions were degassed in order to remove dioxygen and transferred to a capillary. The ESR spectrum shown in Figure 3B reveals the presence of the radical centered isoporphyrin $(\mathrm{g}=2.0026$, linewidth $=6 \mathrm{G})[48]$.

Increasing the concentration of the deposited copolymer on the ITO glass leads to an enhancement of the ESR intensity. Usually, isoporphyrin or radical cations porphyrins are reactive and undergo facile degradation. In this study, poly-ZnT $2 \mathbf{2 i s o}^{\bullet} \cdot \mathbf{P I M}\left(\mathbf{p y}^{+}\right)_{6}$ radical film is unusually stable for more than one year at the solid state (in air). This stability may be due to the electron-withdrawing groups which considerably facilitate the reduction and stabilize the radical cation. It also may be due to the delocalization of the radical through the porphyrin as well as intermolecular $\pi-\pi$-stacking and $\pi$-dimerization between macrocycles.

The deposited film was also studied by scanning atomic force microscopy (AFM) (Figure 3C). Tightly packed coils of the copolymer appear on the surface with an average diameter of ca. 20-50 nm, the height being around $5.0 \mathrm{~nm}$ for the film obtained after 1 iterative scan between $1.1 \mathrm{~V}$ and $+0.9 \mathrm{~V}$ (Figure 3C). The rms surface roughness of the two films have been estimated at $20.0 \mathrm{~nm}$ for poly-ZnT2isoP'-PIM(py $\left.{ }^{+}\right)_{6}$, (calculated from an area of $0.08 \mu \mathrm{m}^{2}$ ). The copolymer obtained after higher iterative scan number exhibited comparable morphology but showed in several positions some aggregation of the coils accompanied by a larger value of the rms surface roughness ( $400 \mathrm{~nm}$ for $\mathrm{n}=15$ ). The formation of coil aggregates might be related to the change of slope of the deposited mass, observed from EQCM measurements in Figure $2 \mathrm{C}$.

The copolymer films were also investigated by X-Ray photoelectron spectroscopy (Figure S4). The analysis of the survey spectra of poly-ZnT2isoP•/PIM(py)6 confirms the presence of the isoporphyrin radical subunits ( $\mathrm{Zn} 2 \mathrm{p} 3$ at $1022.3 \mathrm{eV}, \mathrm{N}$ 1s, and $\mathrm{C} 1 \mathrm{~s}$ peaks), and the presence of the PIM cluster subunits (Mo 3d and I 3d). Furthermore, the signals for F 1s (686.6 eV) is also detected and corresponds to the incorporated counterion $\mathrm{PF}_{6}^{-}$to equilibrate the pyridiniums charges. The $\mathrm{C} 1 \mathrm{~s}$ peaks are composed of three signals at $289.4 \mathrm{eV}$ corresponding to the $\mathrm{C}(\mathrm{O}) \mathrm{OH}$ - in the PIM( $\left.\mathbf{p y}^{+}\right)_{\mathbf{6}}, 286.3 \mathrm{eV}$ and $285.4 \mathrm{eV}$ attributed to homo and hetero (connected to nitrogen) carbon atoms respectively. The N1s peaks reveal the presence of two chemically 
different nitrogen atoms. The contributions at $401.3 \mathrm{eV}$ and $398.5 \mathrm{eV}$ are attributed to the iminic nitrogen and to the reduced pyridinium respectively. Finally, the peak localizated at $394.3 \mathrm{eV}$ might result from the Molybdenum 3p 2/3 orbital.

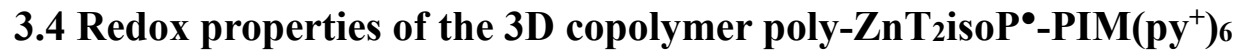

Electroactive copolymers deposited by cyclic voltammetry (n iterative scans) on ITO surfaces have been characterized by electrochemical methods. After electropolymerization, the electrode was then removed from the electrochemical cell, washed with $\mathrm{CH}_{3} \mathrm{CN}$ and used as working electrode in a clean electrolytic solution containing only the solvent and the supporting electrolyte (Figure 4 and Figure S5). The cyclic voltammetry curves shown in Figure 4A have been recorded with copolymers deposited on the ITO electrode surface after various number of scans $(\mathrm{n}=1,3,5,10,15,20$ cycles) between $-1.1 \mathrm{~V}$ and $+0.9 \mathrm{~V}$.

Two successive waves are observed for poly-ZnT $\mathbf{T}_{2} \mathbf{i s o} \mathbf{P}^{\bullet}-\mathbf{P I M}\left(\mathbf{p y}^{+}\right)_{6}$ during the cathodic scan (Table 2 and Figure 4), the first being irreversible (peak b) and the second being quasi-reversible (peak c). The first irreversible wave (peak b) is detected at $-0.72 \mathrm{~V}$ and is very close to the second reduction process (peak c). Peak b corresponds probably to the irreversible reduction of the pyridinium connected to the isoporphyrin close to the pendant hydrogen atom. It generates one radical which reacts rapidly via radical coupling with the radical present onto the isoporphyrin (formation of the $\mathrm{C}-\mathrm{C}$ bound). The peak $\mathrm{d}$ is due to the oxidation of resulting compound obtain after the radical coupling. In peak $\mathrm{d}$ the $\mathrm{C}-\mathrm{C}$ bound is broken to regenerate the starting isoporphyrin radical.

Peak $\mathrm{c}$ is attributed to the quasi-reversible reduction of the second pyridinium connected to the isoporphyrin. 

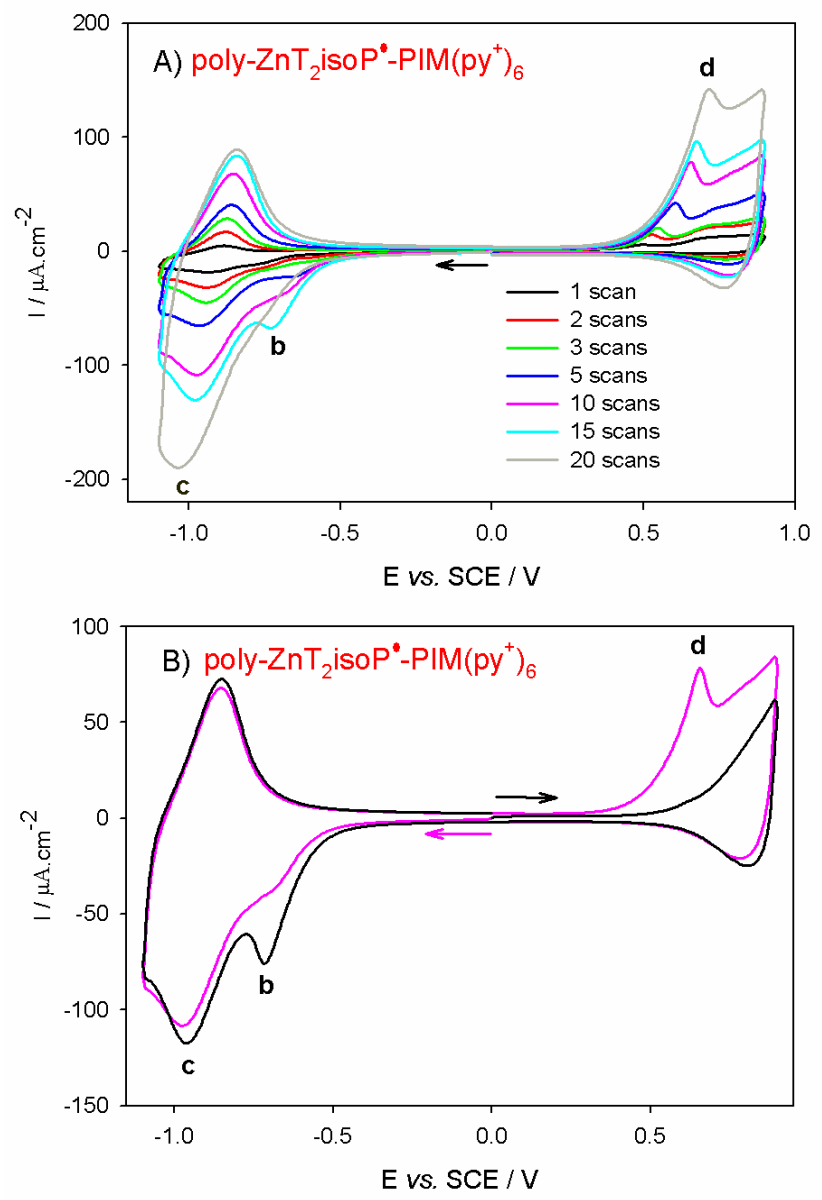

Figure 4. Cyclic voltammograms of poly-ZnT 2 iso $\mathbf{P}^{\bullet}-\mathrm{PIM}\left(\mathrm{py}^{+}\right)_{6}$ obtained with $\mathbf{P I M}(\mathbf{p y})_{6}$ and $\mathrm{ZnT}_{2} \mathbf{P}$ after $\left.\mathrm{A}\right) \mathrm{n}=$ $1,2,3,5,10,15$ and 20 scans and B) after 10 scans between $-1.1 \mathrm{~V}$ and $+0.9 \mathrm{~V}$ in $\mathrm{CH}_{3} \mathrm{CN} / 1,2-\mathrm{C}_{2} \mathrm{H}_{4} \mathrm{Cl}_{2}(3 / 7)$ with $0.1 \mathrm{M} \mathrm{NBu}_{4} \mathrm{PF}_{6}$. WE: ITO. $\mathrm{S}=1 \mathrm{~cm}^{2}, v=100 \mathrm{mV} \mathrm{s}^{-1}$.

When the potential limit chosen is $1.60 \mathrm{~V}$ (and not $0.9 \mathrm{~V}$ ), two oxidation waves appear at 1.10 $\mathrm{V}$ and $1.38 \mathrm{~V}$ as shown in Figure S5. It can be explained by the formation of isoporphyrin cation via oxidation of the isoporphyrin radical followed by the oxidation of the porphyrin which can be formed after the release of the proton. Nevertheless, the deposited film becomes weak and less colored probably indicating partial degradation of the poly-ZnT $\mathbf{T}_{2} \mathbf{i s o} \mathbf{P}^{\bullet}-\mathbf{P I M}\left(\mathbf{p y}^{+}\right)_{6}$ film at this potential.

Table 2. Electrochemical data for $\mathbf{Z n T}_{2} \mathbf{P}$, PIM(py) $)_{6}$, and poly-ZnT $\mathbf{T}_{2} \mathbf{i s o} \mathbf{P}^{\bullet}-\mathbf{P I M}\left(\mathbf{p y}^{+}\right)_{6}$ in $\mathrm{EtCl}_{2} / \mathrm{CH}_{3} \mathrm{CN}(7 / 3)$ solution. Working electrode: ITO.

\begin{tabular}{l|l|l|c|c}
\hline Compounds & Ring oxidation & & $\begin{array}{c}\text { Reduction of the spacer } \\
\left(\mathbf{p y}^{+}, \mathbf{d o u b l e ~ v i o l o g e n ~ o r ~}\right. \\
\text { PIM })\end{array}$ & Ring reduction \\
\hline & & & &
\end{tabular}




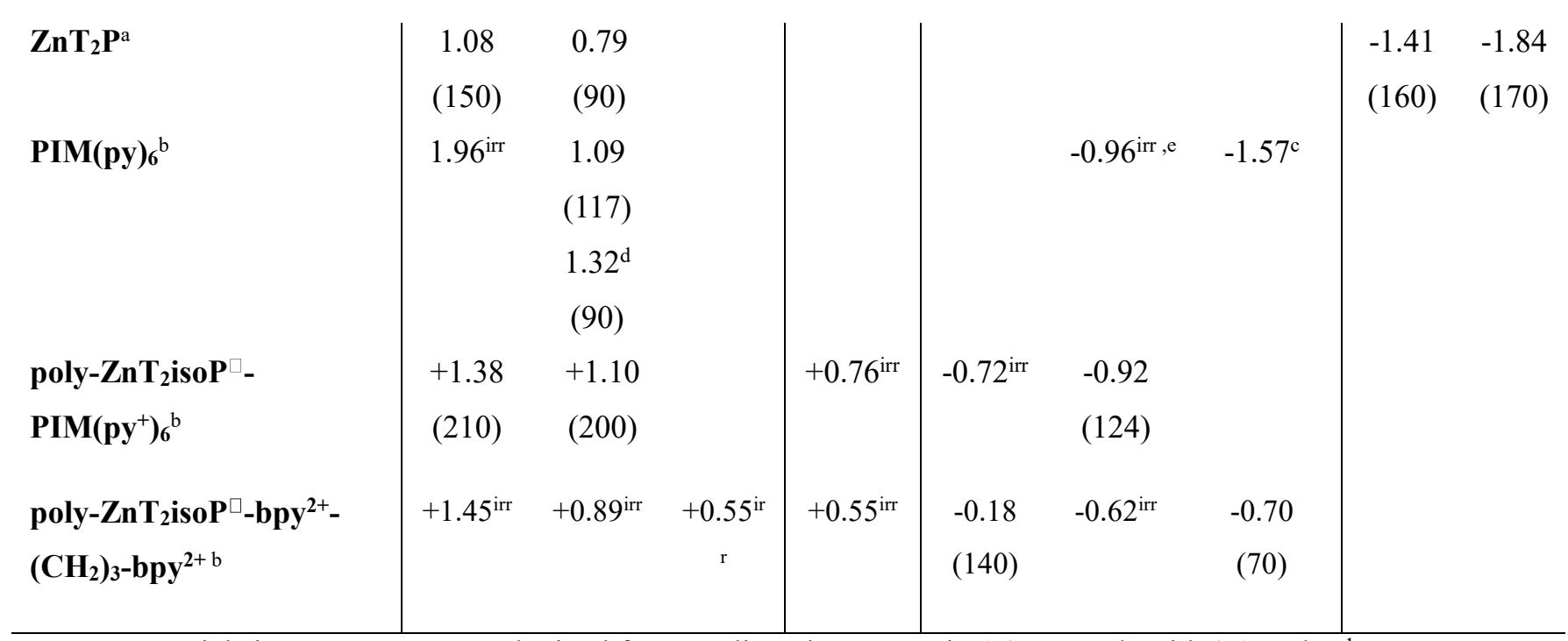

${ }^{\text {a }}$ Potentials in $\mathrm{V} v$ s. SCE were obtained from cyclic voltammetry in $1,2-\mathrm{C}_{2} \mathrm{H}_{4} \mathrm{Cl}_{2}$ with $0.1 \mathrm{~mol} \mathrm{~L}^{-1} \mathrm{TBAPF}_{6}$. Scan rate $=100 \mathrm{mV} \mathrm{s}^{-1}$. Working electrode: ITO, $\mathrm{S}=1 \mathrm{~cm}^{2}$. The given half-wave potentials are equal to $\mathrm{E}_{1 / 2}$ $=\left(\mathrm{E}_{\mathrm{pa}}-\mathrm{E}_{\mathrm{pc}}\right) / 2$. Under bracket: $\triangle \mathrm{Ep}=\left|\mathrm{E}_{\mathrm{pa}}-\mathrm{E}_{\mathrm{pc}}\right|$.

${ }^{b}$ Potentials in V vs. SCE were obtained from cyclic voltammetry in $\mathrm{CH}_{3} \mathrm{CN} / 1,2-\mathrm{C}_{2} \mathrm{H}_{4} \mathrm{Cl}_{2}$ (3/7) with $0.1 \mathrm{~mol}$ $\mathrm{L}^{-1} \mathrm{TBAPF}_{6}$. Scan rate $\mathrm{v}=100 \mathrm{mV} \mathrm{s}^{-1}$.

${ }^{\mathrm{c}}$ if using GC electrode. Nearly the same potential is measured if using Pt electrode.

$\mathrm{d}$ if using GC electrode.

${ }^{\mathrm{e}}$ only observed in the case of the ITO electrode.

\subsection{Impedance and photoelectrochemical properties}

Figures 5A and 5D show the typical current-potential curves of poly-ZnT 2 isoP'-PIM(py $\left.{ }^{+}\right)_{6}(n$ $=1$ or 3 scans) thin films on ITO electrodes obtained in $5 \mathrm{mM} \mathrm{I}_{2} / 0.5 \mathrm{M} \mathrm{I}^{-}$aqueous solution in the dark and under illumination. The potential axis in the cyclic voltammograms is referred to the equilibrium potential of $\mathrm{I}_{3}^{-} / \mathrm{I}^{-}$redox couple in solution. On bare ITO electrode (Figure 5A, grey curve), the $\mathrm{I}^{-}$oxidation and $\mathrm{I}_{3}{ }^{-}$reduction kinetics is slow and almost no Faradaic current is observed between $-0.3 \mathrm{~V}$ and $0.2 \mathrm{~V}$. When the ITO is modified by the poly-ZnT $\mathbf{T}_{2} \mathbf{i s o P} \bullet$ $\operatorname{PIM}\left(\mathbf{p y}^{+}\right)_{6}$ copolymer thin film, significant $\mathrm{I}^{-}$oxidation and $\mathrm{I}_{3}{ }^{-}$reduction current can be seen in the voltammogramms measured in the absence of illumination (dashed curves in Figure 5A and Figure 5D). This demonstrates that the poly-ZnT 2 iso $\mathbf{P}^{\bullet}$-PIM $\left(\mathbf{p y}^{+}\right)_{6}$ copolymer thin film on the ITO electrode acts as an electrocatalyst of $\mathrm{I}^{-}$oxidation and $\mathrm{I}_{3}{ }^{-}$reduction. Similar behaviour was reported with poly-ZnT 2 isoP'-bpy ${ }^{2+}-\left(\mathbf{C H}_{2}\right)_{3}-\mathbf{b p y}^{\mathbf{2 +}}$ copolymer thin films [21].

A typical current-potential curve measured under visible-NIR light illumination (using a long pass filter $\lambda>385 \mathrm{~nm}$ ) is displayed in Figure $5 \mathrm{~A}$ (green full line) for the poly-ZnT $\mathbf{T}_{2} \mathbf{i s o P} \mathbf{P}^{\bullet}$ $\operatorname{PIM}\left(\mathbf{p y}^{+}\right)_{6}$ copolymers obtained for $\mathrm{n}=3$ scans. The open circuit photopotential under illumination is around $0.1 \mathrm{~V}$ and the short-circuit current is of $c a$. $-130 \mu \mathrm{A} \mathrm{cm}^{-2}$ revealing electron injection from the copolymer to $\mathrm{I}_{3}{ }^{-}$in solution under illumination. For a number of electropolymerization potential scans $\mathrm{n}<5$, isoporphyrin copolymers prepared with PIM(py)6 exhibited better photocurrents than the ones prepared with the double viologen spacer under the 
same conditions of electropolymerization (Figure 6B). This can be attributed to the much larger amount of isoporphyrin deposited on the ITO electrode during the initial electropolymerization cycles when PIM(py)6 is used instead 1,1"-(1,3-propanediyl)bis-4,4'-bipyridinium hexafluorophosphate salt $\left(\mathrm{bpy}^{+}\left(\mathrm{CH}_{2}\right)_{3}-\mathrm{bpy}^{+} 2 \mathrm{PF}_{6}{ }^{-}\right)$, as confirmed by the higher intensity of the

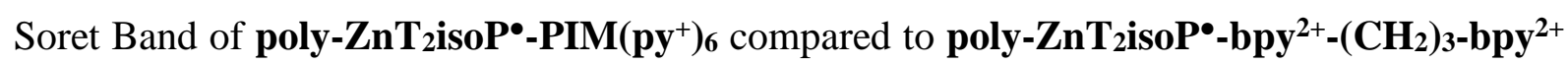
(Figure 6A).

The photocurrent response of poly-ZnT $\mathbf{T}_{2} \mathbf{i s o P}^{\bullet}-\mathbf{P I M}\left(\mathbf{p y}^{+}\right)_{6}$ in the potentiostatic mode at $0 \mathrm{~V}$ under on-off light illumination cycles for various $\mathrm{n}$ is shown in Figures 5B and 5C. For all measurements, reversible rise and decay of the photocurrent in response to the on/off illumination step can be observed. The photocurrent exhibits an optimum value as a function of $\mathrm{n}$ and the copolymer film thickness, the best performance being obtained for $\mathrm{n}=3$ potential scans. Similar behaviour has been previously reported for other "linear" isoporphyrin copolymers, such as poly-ZnT $\mathbf{T}_{2}$ isoP'-bpy ${ }^{2+}-\left(\mathbf{C H}_{2}\right)_{3}-\mathbf{b p y} \mathbf{~}^{2+}$ with double viologen spacer [21]. Note however, that larger of number electropolymerization cycles (around $n=10-15$ ) were

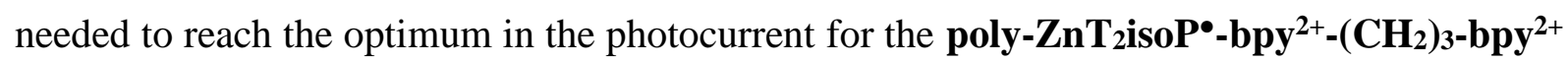
copolymer [21].

To determine the contribution of NIR absorption to the overall photocurrent, the NIR photoresponse was investigated using a longpass filter $\lambda>800 \mathrm{~nm}$. The typical results are plotted in Figure 5D for the copolymer poly-ZnT $2 \mathbf{i s o P}^{\bullet}-\mathbf{P I M}\left(\mathbf{p y}^{+}\right)_{6}$ thin film obtained after only one electropolymerization potential scan. Reproducible and stable photocurrent of ca. -8 $\mu \mathrm{A} \mathrm{cm}^{-2}$ is observed under on/off illumination cycles with the NIR radiation. In general, the ratio of the photocurrent in NIR region to the overall (visible + NIR region) photocurrent (for example $-58 \mu \mathrm{A} \mathrm{cm}^{-2}$ for $\mathrm{n}=1$ electropolymerization cycle) is around $12 \%$ and the open circuit photovoltage is of $c a .50 \mathrm{mV}$ under NIR illumination.

The contribution is even higher in the case of poly-Zn $\mathbf{T}_{2} \mathbf{i s o P} \mathbf{P}^{\bullet}-\mathbf{b p y} \mathbf{y}^{\mathbf{2 +}}-\left(\mathbf{C H}_{2}\right)_{3}-\mathbf{b p y} \mathbf{y}^{\mathbf{2 +}}$ where the ratio of the photocurrent in NIR region to the overall is $26 \%$ (Figure S6). It can be explained by the more intense NIR band in the case of poly-Zn $\mathbf{T}_{2} \mathbf{i s o} \mathbf{P}^{\bullet}-\mathbf{b p y}^{\mathbf{2 +}}-\left(\mathbf{C H}_{2}\right)_{3}-\mathbf{b p y}{ }^{\mathbf{2 +}}[\mathbf{2 1}]$. 

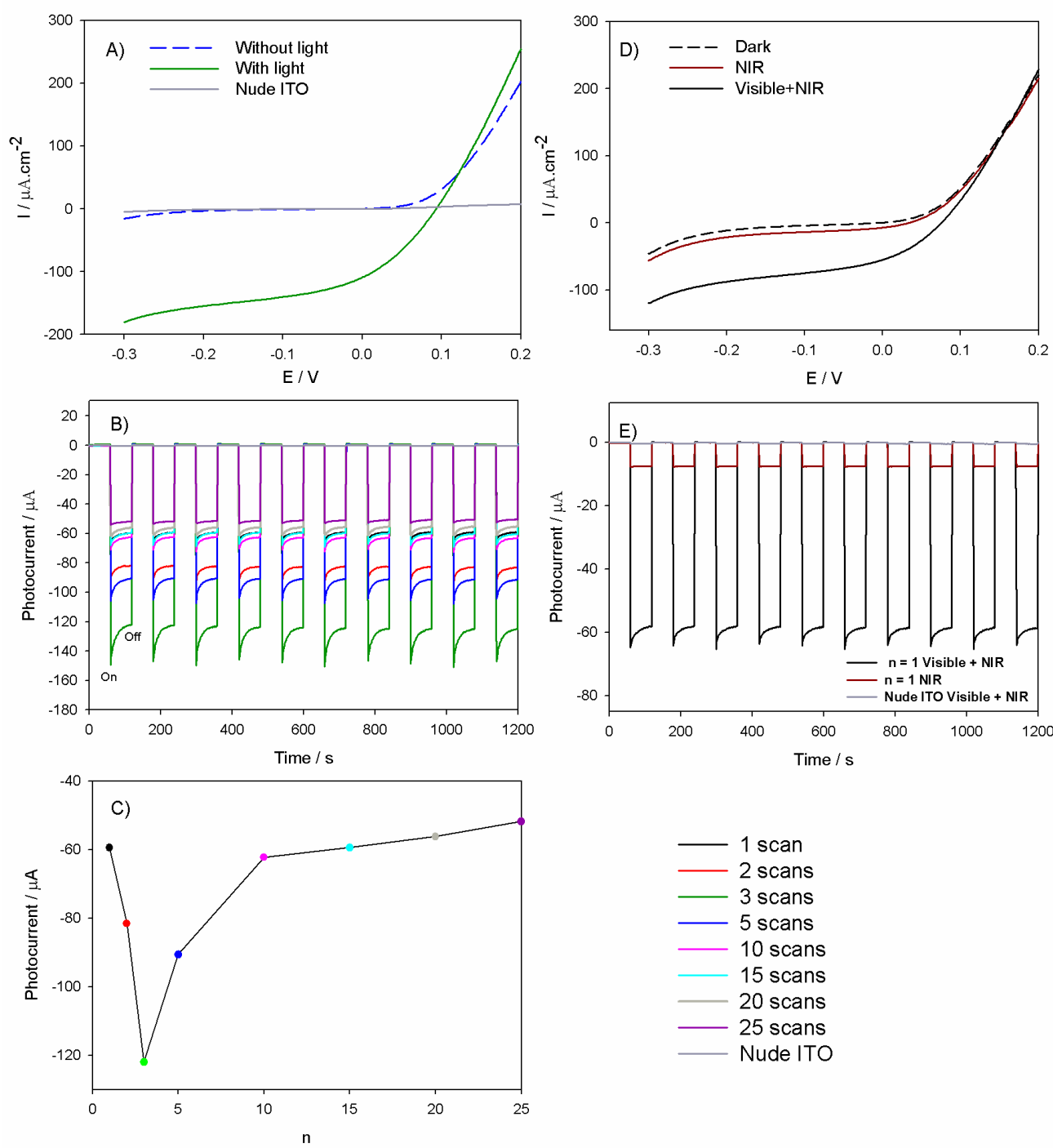

Figure 5. A) Current-potential curves of poly-ZnT ${ }_{2}$ iso $^{\bullet}-\mathbf{P I M}\left(\mathbf{p y}^{+}\right)_{6}$ (obtained with $n=3$ iterative scans between $-1.1 \mathrm{~V}$ and $+0.9 \mathrm{~V}$ thin films on ITO electrodes obtained in $0.5 \mathrm{M} \mathrm{I}^{-} / 5 \mathrm{mM} \mathrm{I}_{2}$ aqueous solution in the dark or under visible illumination. B) and C) Photoelectrochemical responses of poly- $\mathbf{Z n T}_{2} \mathbf{i s o P}^{\bullet}$ $\operatorname{PIM}\left(\mathbf{p y}^{+}\right)_{6}$ films obtained with $\mathrm{n}=1,2,3,5,10,15,20$ or 25 iterative scans. Measurements have been done under on-off light illumination from a $300 \mathrm{~W}$ Xe arc lamp (with $\lambda>385 \mathrm{~nm}$ long pass filter) in $\mathrm{I}_{3}^{-} 5 \mathrm{mmol} \mathrm{L}^{-1}$ and $\mathrm{I}^{-} 0.5 \mathrm{~mol} \mathrm{~L}^{-1}$ aqueous solution. BIAS potential: $0.00 \mathrm{~V}$ vs. OCP. D) Current-potential curves of poly$\mathrm{ZnT}_{2}$ isoP'$^{\bullet}-\mathrm{PIM}\left(\mathrm{py}^{+}\right)_{6}$ (obtained with $\mathrm{n}=1$ scan between $-1.1 \mathrm{~V}$ and $+0.9 \mathrm{~V}$ thin films on ITO electrodes obtained in $0.5 \mathrm{M} \mathrm{I}^{-} / 5 \mathrm{mM} \mathrm{I}_{2}$ aqueous solution in the dark, under visible-NIR illumination or under NIR illumination. 

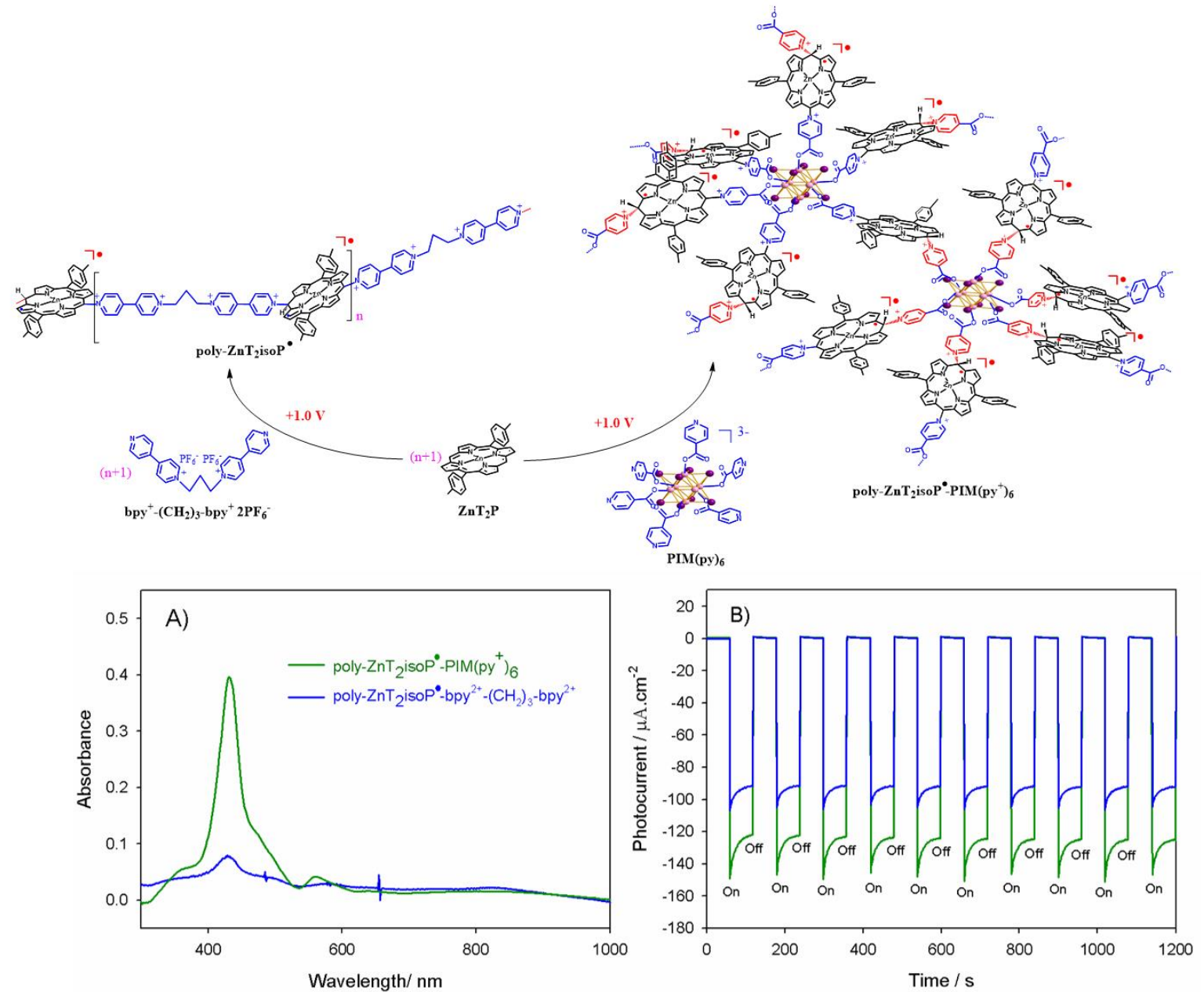

Figure 6. A) UV-visible-NIR absorption spectra of poly-ZnT ${ }_{2}$ isoP'$^{\bullet}-\mathbf{P I M}\left(\mathbf{p y}^{+}\right)_{6}$ compared to poly$\mathbf{Z n T}_{2} \mathbf{i s o P}^{\boldsymbol{\bullet}}-\mathbf{b p y}^{\mathbf{2 +}}-\left(\mathbf{C H}_{2}\right)_{3}-\mathbf{b p y}^{\mathbf{2 +}}$ onto ITO obtained after $\mathrm{n}=3$ iterative scans between -1.1 and $+0.9 \mathrm{~V} v s$. $\operatorname{SCE}\left(v=100 \mathrm{mV} \mathrm{s}^{-1}\right)$. Only one side of the slide is covered by ITO. B) Photoelectrochemical responses of poly-ZnT ${ }_{2}$ isoP $^{\bullet}-\mathbf{P I M}\left(\mathrm{py}^{+}\right)_{6}$ and of poly-ZnT $\mathbf{T}_{2}$ iso $^{\bullet}-$ bpy $^{2+}-\left(\mathbf{C H}_{2}\right)_{3}-\mathbf{b p y}^{2+}$ obtained with $\mathrm{n}=3$ iterative scans. Measurements have been done under on-off light illumination from a $300 \mathrm{~W}$ Xe arc lamp (with $\lambda>385 \mathrm{~nm}$ long pass filter) in $\mathrm{I}_{3}^{-} 5 \mathrm{mmol} \mathrm{L}^{-1}$ and $\mathrm{I}^{-} 0.5 \mathrm{~mol} \mathrm{~L}^{-1}$ aqueous solution. BIAS potential: $0.00 \mathrm{~V} v s$. OCP.

Figure 7 shows the EIS spectra obtained for poly-ZnT $\mathbf{T}_{2} \mathbf{i s o} \mathbf{P}^{\bullet}-\mathbf{P I M}\left(\mathbf{p y}^{+}\right)_{6}$ and $\mathbf{p o l y}-\mathbf{Z n T}_{2} \mathbf{i s o} \mathbf{P}^{\bullet}-$ bpy $^{2+}-\left(\mathbf{C H}_{2}\right)_{3}-\mathbf{b p y} \mathbf{y}^{2+}$ under illumination, using a perturbation of $10 \mathrm{mV}$ over the open circuit photopotential. Experimental data are represented by circles while the solid lines correspond to the fit obtained using the equivalent circuit shown in Figure S7. The general behaviour of the

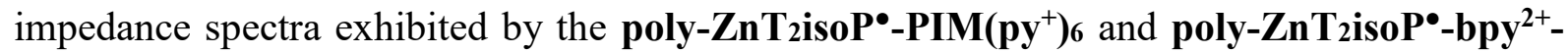
$\left(\mathbf{C H}_{2}\right)_{3}-\mathbf{b p y}^{2+}$ copolymer are similar. The Nyquist diagrams of the copolymers prepared with one electropolymerization cycle (Figure 7A) possess one semicircle at high frequency followed by a straight line at low frequency, which can be well described by a charge transfer resistance $\mathrm{R}_{\mathrm{ct}}$ and a Warburg impedance in parallel with the interfacial capacitance $\mathrm{C}_{\mathrm{i}}$. For $\mathrm{n}=1$, the charge transfer resistance of the poly-ZnT 2 iso $\mathbf{P}^{\bullet}-\mathbf{P I M}\left(\mathbf{p y}^{+}\right)_{6}$ copolymer (ca. $270 \Omega$ ) is significantly lower than the one of poly-ZnT $\mathbf{T}_{2}$ iso $\mathbf{P}^{\bullet}-\mathbf{b p y}^{\mathbf{2 +}}-\left(\mathbf{C H}_{2}\right)_{3}-\mathbf{b p y} \mathbf{y}^{2+}$ (ca. $680 \Omega$ ). This difference is in 
line with the higher photocurrent obtained with poly-Zn $\mathbf{T}_{2} \mathbf{i s o P}^{\bullet}-\mathbf{P I M}\left(\mathbf{p y}^{+}\right)_{6}$ and is obviously due to the larger amount of isoporphyrin deposited on the ITO electrode during the first potential scan. When the thickness of the copolymer films increases, a second semicircle appears in the Nyquist plots, as can be seen in Figure 7B. The second loop is attributed to an additional charge transfer resistance in the copolymer film, and could be described by including the contribution of $\mathrm{R}_{\text {film }}$ in parallel with $\mathrm{C}_{\mathrm{f}}$ the capacitance of the film in the equivalent circuit (Figure S7).

The values of $R_{c t}$ and $R_{\text {film }}$ extracted from the fit as a function of $n$ are plotted in Figures $8 \mathrm{~A}$ and

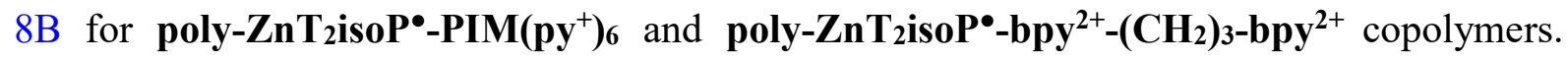
When the number of electropolymerization cycles increases, the charge transfer resistance $R_{c t}$ of both copolymer first decreases with $\mathrm{n}$, indicating a good electrochemical contact and fast electron transfer between the deposited isoporphyrin copolymer, the ITO electrode and $\mathrm{I}_{3}{ }^{-}$in solution. For $n>5$, $R_{c t}$ reaches a constant value (ca. $20 \Omega$ ) suggesting that the ITO surface is fully covered by the copolymer. Interestingly, the EIS spectra of poly-Zn $\mathbf{T}_{2} \mathbf{i s o P} \bullet-\mathbf{P I M}\left(\mathbf{p y}^{+}\right)_{6}$ exhibit a strong increase of the film resistance $\mathrm{R}_{\text {film }}$ for $\mathrm{n}>3$, in contrast to the poly-Zn $\mathbf{Z} \mathbf{T}_{2} \mathbf{i s o} \mathbf{P}^{\bullet}$ $\mathbf{b p y}^{2+}-\left(\mathbf{C H}_{2}\right)_{3}-\mathbf{b p y} \mathbf{y}^{2+}$ copolymer, for which the $\mathrm{R}_{\text {film }}$ only slightly increases with $\mathrm{n}$. The influence of $\mathrm{R}_{\text {film }}$ on the EIS spectra can be clearly seen in the Nyquist diagrams of the two copolymers obtained for $\mathrm{n}=20$ scans (Figure 7B), the overall impedance of the poly-Zn $\mathbf{T}_{2} \mathbf{i s o P} \mathbf{P}^{\bullet}-\mathbf{P I M}\left(\mathbf{p y}^{+} \mathbf{}_{\mathbf{6}}\right.$ being significantly higher than the one of poly-ZnT $\mathbf{T}_{2} \mathbf{i s o} \mathbf{P}^{\bullet}-\mathbf{b p y}^{\mathbf{2 +}}-\left(\mathbf{C H}_{2}\right)_{3}-\mathbf{b p y} \mathbf{y}^{\mathbf{2 +}}$. The

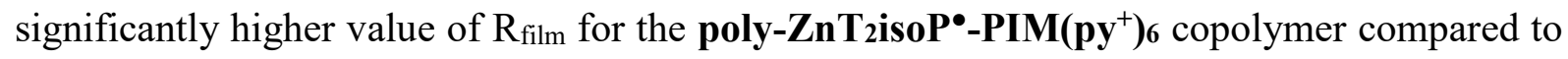
poly-ZnT $\mathbf{T}_{2}$ isoP $^{\bullet}-\mathbf{b p y}^{\mathbf{2 +}}-\left(\mathbf{C H}_{2}\right)_{3}-\mathbf{b p y}^{2+}$ shed light on the influence of the copolymer structure on its photoelectrochemical properties, the electron transfer between the isoporphyrin and either the ITO electrode or the $\mathrm{I}_{3}$ " in solution becoming much slower when the thickness of the "3D" structured poly-ZnT $\mathbf{T}_{2} \mathbf{i s o} \mathbf{P}^{\bullet}-\mathbf{P I M}\left(\mathbf{p y}^{+}\right)_{6}$ copolymer increases. 

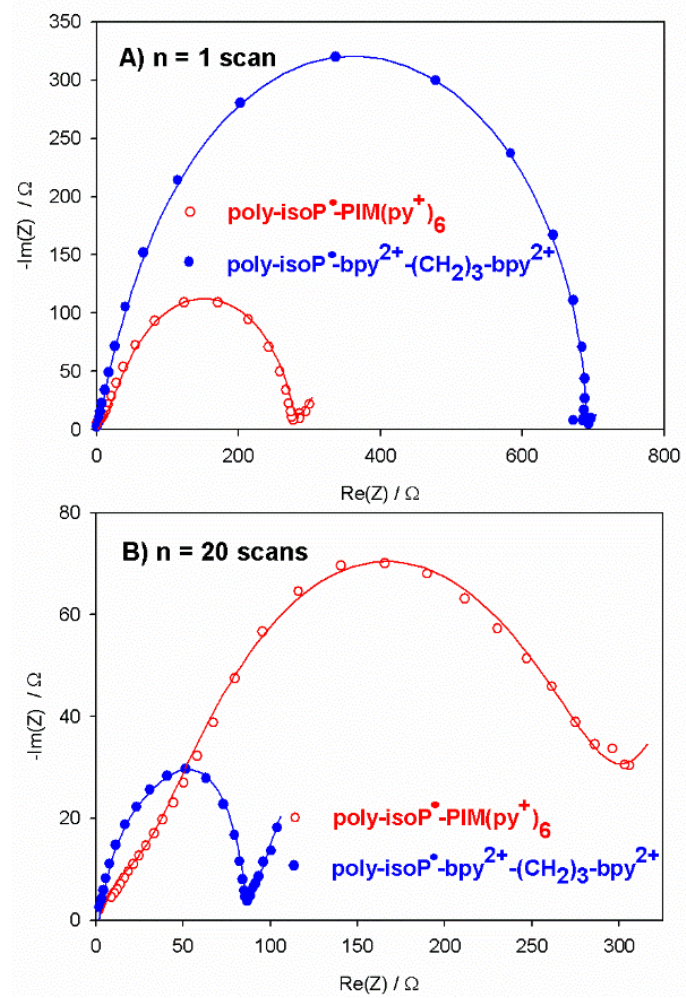

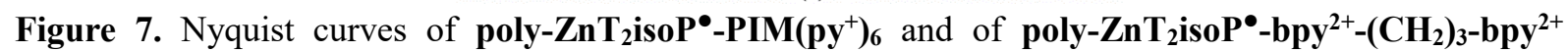
(obtained with iterative scans between $-1.1 \mathrm{~V}$ and $+0.9 \mathrm{~V}$ ) on ITO electrodes obtained in $0.5 \mathrm{M} \mathrm{I}^{-} / 5 \mathrm{mM} \mathrm{I}_{2}$ aqueous solution under light irradiation. A) $n=1$ scan, B) $n=20$ scans.
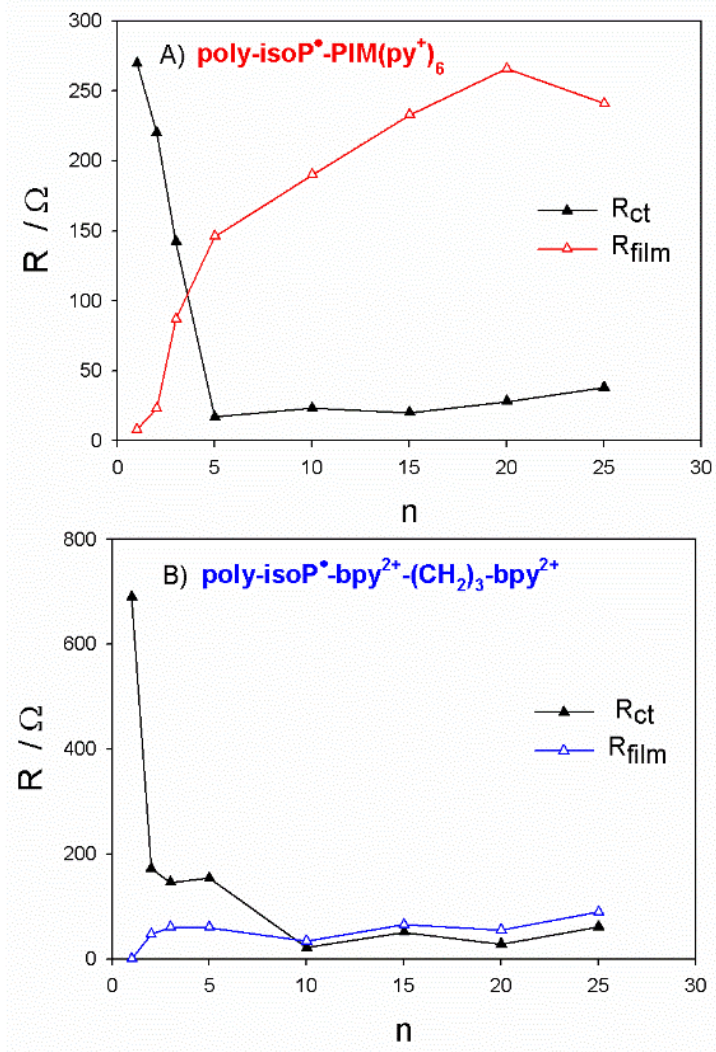

Figure 8. Plot of the $\mathrm{R}_{\mathrm{ct}}$ and $\mathrm{R}_{\text {film }}$ of the thin films versus $\mathrm{n}$ (number of iterative scan, $v=100 \mathrm{mV} \mathrm{s}^{-1}$, between $-1.1 \mathrm{~V}$ and $+0.9 \mathrm{~V})$. A) poly-ZnT $\left.\mathbf{T}_{2} \mathbf{i s o}^{\bullet} \mathbf{P}^{\bullet} \mathbf{P I M}\left(\mathbf{p y}^{+}\right)_{6}, \mathrm{~B}\right)$ poly-ZnT $\mathbf{T}_{2} \mathbf{i s o P}^{\bullet}-\mathbf{b p y}^{2+}-\left(\mathbf{C H}_{2}\right)_{3}-$ bpy $^{2+}$. 
Scheme 2 represents the energy diagram corresponding to the photoreduction of $\mathrm{I}_{3}{ }^{-}$on the copolymer poly-ZnT $\mathbf{T}_{2}$ isoP•-PIM(py $\left.{ }^{+}\right)_{6}$. In the former research of our group [14a,49], the inclusion of polyoxometalates (POMs) was found to be beneficial to the photocurrent due to the enhanced electron transfer kinetics from the excited porphyrin of the copolymers to the pyridinum giving the radical pyridyl $\left(\mathrm{py}^{\bullet}\right)$, which in turn can give one electron to the POM moieties. This cascade of electron transfer allows to avoid the back recombination between the radical cation porphyrin and the radical pyridyl $\left(\mathrm{py}^{\bullet}\right)$.

The HOMO level energies of the poly-Zn $\mathbf{T}_{2} \mathbf{i s o P}^{\bullet}-\mathbf{P I M}\left(\mathbf{p y}^{+}\right)_{6}$ have been estimated from the first oxidation potential observed in the cyclic voltammograms, while the energy level of the dipyridinium species is given by the potential of the first and second reduction peaks (Table 2). The LUMO levels of the excited poly-ZnT $\mathbf{2}$ isoP'-PIM $\left(\mathbf{p y}^{+}\right)_{6}$ species can be roughly estimated by subtracting the excitation energy of the Soret or Q bands from the HOMO level energies. The energy level corresponding to the band in the NIR region has also been indicated in the energy diagram. The energy level of the PIM(py)6/PIM(py)6 at $-3.78 \mathrm{eV}$ can be calculated from the potential of reduction of PIM(py)6 $(-4.50-(-0.72)=-3.78 \mathrm{eV})$.

Under illumination under short-circuit current conditions, the photon absorption by the (iso)porphyrin entities generates an electron hole pair in the copolymer. The electron is transferred from the excited isoporphyrins radical subunit, to the pyridinum subunit which is reduced to form the radical pyridyle py (dotted red arrow in Scheme 2). The pyridinium acts as a relay for the electron transfer. Then, the radical pyridyle py in turn can reduce $\mathrm{I}_{3}{ }^{-}$into $\mathrm{I}^{-}$ which is reoxidized at the counter electrode. The oxidized isoporphyrin is regenerated by an electron transfer from the ITO substrate.

As the energy level of the NIR band associated to the isoporphyrin radical subunit is lower than the energy level of the couple $\mathrm{Py}^{+} / \mathrm{Py}^{\bullet}$, after non radiative relaxation, the electron also could be transferred directly from NIR energy level to the level $\mathrm{I}_{3}^{-} / \mathrm{I}^{-}$to reduce $\mathrm{I}_{3}{ }^{-}$to $\mathrm{I}^{-}$, which could explain the photocurrent generated by copolymer poly-ZnT $\mathbf{T}_{2} \mathbf{i s o P}^{\bullet}-\mathbf{P I M}\left(\mathbf{p y}^{+}\right)_{6}$ under NIR illumination. In such a case, PIM(py)6 is not mediating the electron transfer.

However, it should be noticed that the PIM(py)6 can also accept electron from the excited isoporphyrins radical subunit giving the reduced form PIM(py) $\mathbf{6}^{-}$but only in the case of the levels S2 (Soret bands) as well as the more energetic level S1 corresponding to the Q band as shown in Scheme 2 (blue arrows). In such a case, the reduced PIM(py)6 can in turn give one electron to the pyridium subunit to form the radical pyridyle $\mathrm{Py}^{\bullet}$. Finally, the $\mathrm{Py}^{\bullet}$ can exchange electron with $\mathrm{I}_{3}{ }^{-}$giving $\mathrm{I}^{-}$which is reoxidized at the counter electrode. 
It must be mentioned that PIM(py)6 can also be directly excited using visible light, its UVvisible spectrum exhibiting broad band at $402 \mathrm{~nm}$ corresponding to the $\left\{\mathrm{Mo}_{6} \mathrm{I}_{8}\right\}^{4+}$ core-centered $\mathrm{d}-\mathrm{d}$ transitions. The excited PIM(py)6 becomes a good electron donor and can give the electron to the pyridinium group as reported in Figure S8. However, the intensity of this band is low compared to isoporphyrin moieties and the contribution to the overall photocurrent is expected to be small.

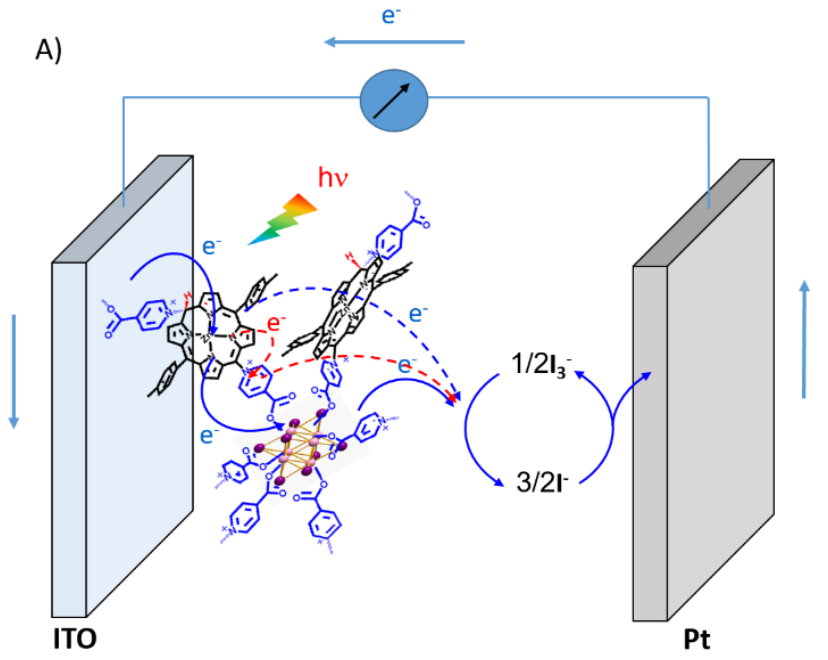

B)

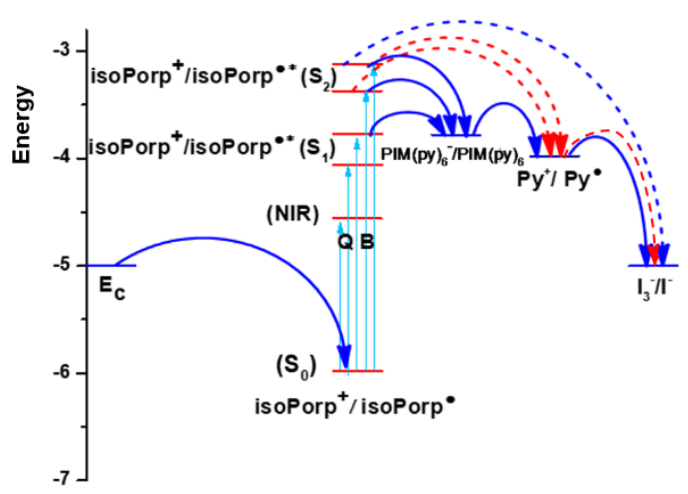

Scheme 2. Schematic illustration of the energy level diagram for poly-Zn $\mathbf{T}_{2} \mathbf{i s o P}^{\bullet}$-PIM( $\left.\mathbf{p y}^{+}\right)_{\mathbf{6}}$ showing electron transfer processes in $\mathrm{H}_{2} \mathrm{O}$ containing $\mathrm{I}_{3}^{-} 5 \mathrm{mmol} \mathrm{L}^{-1}$ and $\mathrm{I}^{-} 0.5 \mathrm{~mol} \mathrm{~L}^{-1}\left(\mathrm{Py}^{+}=\right.$ pyridinium, Porp $=$ porphyrin) under light irradiation.

\section{Conclusion}

In summary, 3D copolymer films have been prepared by the electro-oxidation of 5,15ditolylporphyrin $\left(\mathbf{Z n T}_{2} \mathbf{P}\right)$ in the presence of polyiodometalate with 6 pendant pyridyl ligands $\left(\mathrm{Bu}_{4} \mathrm{~N}\right)_{2}\left[\mathrm{Mo}_{6} \mathrm{I}_{8}(\text { pyCOO})_{6}\right]\left(\mathbf{P I M}(\mathbf{p y})_{6}\right)$. Electrogenerated radical cation porphyrin $\mathbf{Z n T}_{2} \mathbf{P}^{+\bullet}$ is a powerful electrophile which can rapidly react to form copolymer containing stable isoporphyrins (poly-ZnT $\left.\mathbf{T}_{\mathbf{2}} \mathbf{s o P}^{\bullet}-\mathbf{P I M}\left(\mathbf{p y}^{+}\right)_{\mathbf{6}}\right)$. The existence of the cation radical of the isoporphyrin was proved by electron spin resonance spectroscopy. The achieved copolymers were characterized by UV-Vis-NIR spectroscopy, Atomic Force Microscopy and X-ray photoelectron spectroscopy. Electrochemical properties of these copolymers have been discussed and studied.

The photocurrent measurements under visible-NIR light irradiation show that poly-ZnT $\mathbf{2}$ isoP• $\mathbf{P}^{\bullet}$ 
$\operatorname{PIM}\left(\mathbf{p y}^{+}\right)_{6}$ thin films exhibit significantly performance even under only NIR illumination. However, the photovoltaic performances reach an optimum depending on the number of electropolymerization potential scan $n$. The best performances are obtained for $n=3$. Therefore, the control of the thickness of the copolymer films is of great importance to optimize the generation of photocurrent under visible illumination. Furthermore, the results proved that the NIR band played an important role for photocurrent measurement where the contribution is noticeable.

Poly-ZnT TisoP $^{\bullet}$-PIM( $\left(\mathbf{p y}^{+}\right)_{6}$ in the solid state could be stored for over several months and even one year without any degradation under ambient conditions in air. Further investigations are underway in order to understand more about this notable stability. Other type of stable isoporphyrin radical are in preparation in our laboratory.

\section{Acknowledgements}

We thank CNRS, the Université de Strasbourg (France), Université Paris-Descartes (Paris, France), for funding of this work. We also thank the Université de Strasbourg for Labex CSC (Chemistry of Complex Systems) which has also supported one part of this research as well as the CSC (China Scholarship Council) grant for the Ph.D. grant of Yiming Liang.

\section{Appendix A. Supplementary data}

Supplementary data related to this article can be found at https://doi.org/10.1016/j.electacta.2020....

Content of the supplementary data: experimental details, electrochemistry, EQCM, UV-Vis spectra, XPS, AFM, EIS, and photoelectrochemical responses (Figs. S1-S8, Scheme S1-S3, Tables S1-S2).

\section{Author contributions}

Laurent Ruhlmann conceived the idea, and initiated the study. He wrote the manuscript with the assistance of all the co-authors. Yiming Liang carried out the preparation and 
characterization of the copolymers as well the EIS and photovoltaic measurements. Maxim N. Sokolov and Maxim A. Mikhaylov have prepared the PIM(py)6 and also participate to the discussion of this work. Helen Ibrahim and Michel Goldmann have done the AFM measurements. Sylvie Choua and Nolwenn Le Breton have done the ESR measurments and analysis. Antoine Bonnefont, Corinne Boudon and Vasilica Badets contributed to the analysis of the EQCM, EIS as well as photocurrent measurements. They also helped to write the manuscript. All authors discussed the results and commented on the manuscript.

\section{Graphical abstract}

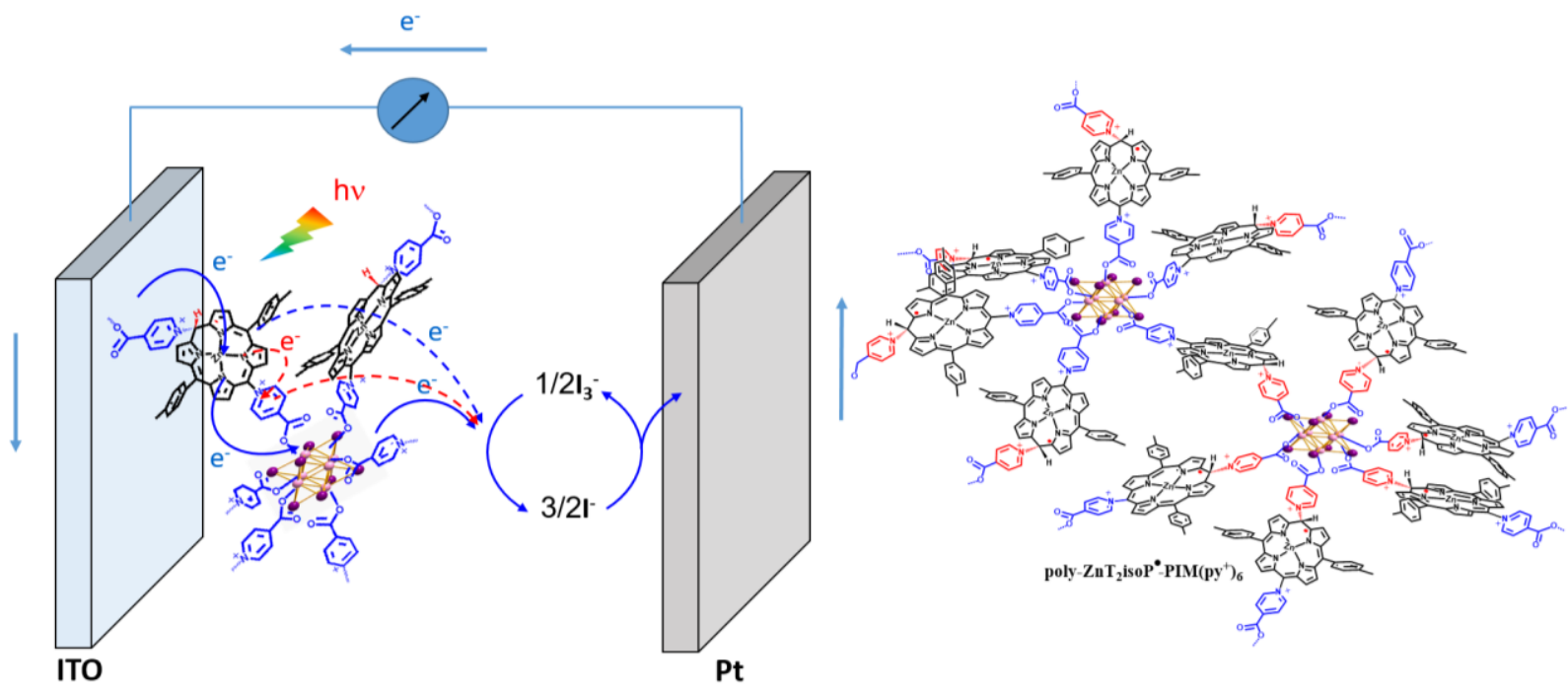

First example of formation of a 3D hybrid organic-inorganic copolymer based on an isoporphyrin and on a pyridine end-decorated molybdenum(II) halide cluster. The electrical properties and the photovoltaic performances have been investigated under visible-NIR light irradiation.

\section{References}

[1] D.-L. Long, R. Tsunashima, L. Cronin, Polyoxometalates: building blocks for functional nanoscale systems, Angew. Chem. Int. Edit. 49 (2010) 1736-1758; Polyoxometallate als bausteine für funktionelle nanosysteme, Angew. Chem. Int. Ed. 122 (2010) 1780-1803. 
[2] M. V. Volostnykh, M. A. Mikhaylov, A. A. Sinelshchikova, G. A. Kirakosyan, A. G. Martynov, M. S. Grigoriev, D. A. Piryazev, A. Yu. Tsivadze, M. N. Sokolov, Y. G. Gorbunova, Hybrid organicinorganic supramolecular systems based on a pyridine end-decorated molybdenum(II) halide cluster and zinc(ii) porphyrinate, Dalton Trans. 48 (2019) 1835-1842.

[3] M. N. Sokolov, M. A. Mihailov, E. V. Peresypkina, K. A. Brylev, N. Kitamura and V. P. Fedin, Highly luminescent complexes $\left[\mathrm{Mo}_{6} \mathrm{X}_{8}\left(\mathrm{n}_{-} \mathrm{C}_{3} \mathrm{~F}_{7} \mathrm{COO}\right)_{6}\right]^{2-}(\mathrm{X}=\mathrm{Br}$, I), Dalton Trans. 40 (2011) 63756377.

[4] M. A. Mikhailov, K. A. Brylev, A. V. Virovets, M. R. Gallyamov, I. Novozhilov, M. N. Sokolov, Complexes of $\left\{\mathrm{Mo}_{6} \mathrm{I}_{8}\right\}$ with nitrophenolates: synthesis and luminescence, New J. Chem. 40 (2016) $1162-1168$.

[5] C. Felip-León, C. Arnau del Valle, V. Pérez-Laguna, M. Isabel Millán-Lou, J. F. Miravet, M. Mikhailov, M. N. Sokolov, A. Rezusta-López, F. Galindo, Superior performance of macroporous over gel type polystyrene as a support for the development of photo-bactericidal materials, J. Mater. Chem. B, 5 (2017) 6058-6064.

[6] A. Beltrán, M. Mikhailov, M. N. Sokolov, V. Pérez-Laguna, A. Rezusta, M. J. Revillo and F. Galindo, A photobleaching resistant polymer supported hexanuclear molybdenum iodide cluster for photocatalytic oxygenations and photodynamic inactivation of Staphylococcus aureus, J. Mater. Chem. B, 4 (2016) 1-5.

[7] M. A. Mikhailov, K. A. Brylev, P. A. Abramov, E. Sakuda, S. Akagi, A. Ito, N. Kitamura and M. N. Sokolov, Synthetic tuning of redox, spectroscopic, and photophysical properties of $\left\{\mathrm{Mo}_{6} \mathrm{I}_{8}\right\}^{4+}$ core cluster complexes by terminal carboxylate ligands, Inorg. Chem. 55 (2016) 8437-8445.

[8] K. Kirakci, P. Kubát, M. Dusek, K. Fejfarová, V. Šícha, J. Mosinger, K. Lang, Eur. J. Inorg. Chem. (2012) 3107-3111.

[9] K. Kirakci, P. Kubát, M. Kuceráková, V. Šícha, H. Gbelcová, P. Lovecká, P. Grznárová, T. Ruml, K. Lang, Water-soluble octahedral molybdenum cluster compounds $\mathrm{Na}_{2}\left[\mathrm{Mo}_{6} \mathrm{I}_{8}\left(\mathrm{~N}_{3}\right)_{6}\right]$ and $\mathrm{Na}_{2}\left[\mathrm{Mo}_{6} \mathrm{I}_{8}(\mathrm{NCS})_{6}\right]$ : Syntheses, luminescence, and in vitro studies, Inorg. Chim. Acta, 441 (2016) 42-49. [10] L. Riehl, A. Seyboldt, M. Ströbele, D. Enseling, T. Jüstel, M. Westberg, P. R. Ogilbyc, H.-J. Meyer, Water-soluble octahedral molybdenum cluster compounds $\mathrm{Na}_{2}\left[\mathrm{Mo}_{6} \mathrm{I}_{8}\left(\mathrm{~N}_{3}\right)_{6}\right]$ and $\mathrm{Na}_{2}\left[\mathrm{Mo}_{6} \mathrm{I}_{8}(\mathrm{NCS})_{6}\right]$ : Syntheses, luminescence, and in vitro studies, Dalton Trans., 45 (2016) 15500-15506.

[11] L. Ruhlmann, A. Schulz, A. Giraudeau, C. Messerschmidt, J.-H. Fuhrhop, A polycationic zinc5,15-dichlorooctaethylporphyrinate-viologen wire, J. Am. Chem. Soc. 121 (1999) 6664-6667.

[12] L. Ruhlmann, J. Hao, Z. Ping, A. Giraudeau, Self-oriented polycationic copolymers obtained from bipyrinium meso-substituted-octaethylporphyrins, J. Electroanal. Chem. 621 (2008) 22e30.

[13]Y. Xia, D. Schaming, R. Farha, M. Goldmann, and L. Ruhlmann, Bis-porphyrin copolymers covalently linked by pyridinium spacers obtained by electropolymerization from $\beta$-octaethylporphyrins and pyridyl-substituted porphyrins, New J. Chem, 36 (2012) 588-596.

[14] a) Z. Huo, D. Zang, S. Yang, R. Farha, M. Goldmann, B. Hasenknopf, H. Xu, and L. Ruhlmann, Synthesis and characterization of Lindqvist-type polyoxometalate-porphyrin copolymers, Electrochimica Acta, 179 (2015) 326-335. b) I. Azcarate, Z. Huo, R. Farha, M. Goldmann, H. Xu, B. Hasenknopf, E. Lacôte, and L. Ruhlmann, Generation of photocurrent by visible-light irradiation of conjugated Dawson polyoxophosphovanadotungstate-porphyrin copolymers, Chem-Eur. J.,21 (2015) 8271-8280. c) Z. Huo, Y. Liang, Y. Lv, F. Melin, P. Hellwig, H. Ibrahim, M. Goldmann, C. Boudon, V. Badets, A. Bonnefont, and L. Ruhlmann, Enhancement of photocurrent by incorporation of Preyssler type polyoxometalate protected nanoparticles in polyporphyrin films, Chem. Comm. 57 (2021) 14821485. d) Z. Huo, S. Yang, D. Zang, R. Farha, M. Goldmann, H. Xu, B. Antoine, G. Izzet, A. Proust, and L. Ruhlmann, Photocurrent generation from visible light irradiation of covalent polyoxometalateporphyrin copolymer", Electrochimica Acta, 368 (2021) 137635.

[15] J. B. Strong, G. P. A. Yap, R. Ostrander, L. M. Liable-Sands, A. L. Rheingold and R. Thouvenot, A New Class of Functionalized Polyoxometalates: Synthetic, Structural, Spectroscopic, and Electrochemical Studies of Organoimido Derivatives of $\left[\mathrm{Mo}_{6} \mathrm{O}_{19}\right]^{2-}$, J. Am. Chem. Soc., 122 (2000) 639649.

[16] T. Zhang, W. Guan, S. Z. Wen, T. Y. Ma, L. K. Yan and Z. M. Su, Theoretical studies on 
metalloporphyrin-polyoxometalates hybrid complexes for dye-sensitized solar cells, J. Phys. Chem. C, 118 (2014) 29623-29628.

[17] J. Hao, A. Giraudeau, Z. Ping, and L. Ruhlmann, supramolecular assemblies obtained by large counteranion incorporation in a well-Oriented polycationic copolymer, Langmuir, 24 (2008) 1600-1603. [18] A. Giraudeau, L. Ruhlmann, L. El-Kahef, M. Gross, Electrosynthesis and characterization of symmetrical and unsymmetrical linear porphyrin dimers and their precursor monomers, J. Am. Chem. Soc. 118 (1996) 2969.

[19] L. Gong, D. Dolphin, Nitrooctaethylporphyrins: synthesis, optical and redox properties, Can. J. Chem. 63 (1985) 401e405.

[20] H. Xie, K.M. Smith, Stable isoporphyrin chromophores: synthesis, Tetrahedron Lett. 33 (1992) $1197 \mathrm{e} 1200$.

[21] M. Boudiaf, Y. Liang, R. Lamare, J. Weiss, H. Ibrahim, M. Goldmann, Embarek Bentouhami, V. Badets, S. Choua, N. Le Breton, A. Bonnefont, L. Ruhlmann, Stable isoporphyrin copolymer: electrochemical mechanism and behaviour and photovoltaic properties, Electrochimica Acta, 309 (2019) 432-449.

[22] J .S. Manka, D.S. Lawrence, High yield synthesis of 5,15-diarylporphyrins, Tetrahedron Lett. 30 (1989) 6989e6992.

[23] T. Takanami, M. Hayashi, H. Chijimatsu, W. Inoue, K. Suda, Palladiumcatalyzed cyanation of porphyrins utilizing cyanoethylzinc bromide as an efficient cyanide ion source, Org. Lett. 7 (2005) $3937 \mathrm{e} 3940$.

[24] B. Habermeyer, A. Takai, C. P. Gros, M. El Ojaimi, J.-M. Barbe, S. Fukuzumi, Dynamics of closure of zinc bis-porphyrin molecular tweezers with copper(II) ions and electron transfer, Chem. Eur J. 17 (2011) 10670e10681.

[25] C. Brückner, J. J. Posakony, C.K. Johnson, R.W. Boyle, B.R. James, D. Dolphin, Novel and improved syntheses of 5,15-diphenylporphyrin and its dipyrrolic precursors, J. Porphyr. Phthalocyanines 2 (1998) 455e465.

[26] K. Kirakci, P. Kubát, M. Dusek, K. Fejfarová, V. Š́cha, J. Mosinger, K. Lang, A highly luminescent Hexanuclear molybdenum cluster - A promising candidate toward photoactive materials, Eur. J. Inorg. Chem. 2012, 3107-3111.

[27] K. Kirakci, P. Kubát, M. Kuceráková, V. Šícha, H. Gbelcová, P. Lovecká, P. Grznárová, T. Ruml, K. Lang, Water-soluble octahedral molybdenum cluster compounds $\mathrm{Na}_{2}\left[\mathrm{Mo}_{6} \mathrm{I}_{8}\left(\mathrm{~N}_{3}\right)_{6}\right]$ and $\mathrm{Na}_{2}\left[\mathrm{Mo}_{6} \mathrm{I}_{8}(\mathrm{NCS})_{6}\right]$ : Syntheses, luminescence, and in vitro studies, Inorganica Chimica Acta, 441 (2016) 42-49.

[28] J. A. Jackson, C. Turro, M. D. Newsham, and D. G. Nocera, Oxygen quenching of electronically excited hexanuclear molybdenum and tungsten halide clusters, J. Phys. Chem. 1990, 94, 4500-4507.

[29] L. Riehl, A. Seyboldt, M. Ströbele, D. Enseling, T. Jüstel, M. Westberg, P. R. Ogilbyc, H.-J. Meyer, A ligand substituted tungsten iodide cluster: luminescence vs. singlet oxygen production, Dalton Trans., 2016, 45, 15500-15506.

[30] A. Fuhrmann, A. Seyboldt, A. Schank, G. Zitzer, B. Speiser, D. Enseling, T. Jüstel, H. Meyer, Luminescence quenching of ligand-substituted molybdenum and tungsten halide clusters by oxygen and their oxidation electrochemistry, Eur. J. Inorg. Chem. 2017, 4259-4266.

[31] . A. Vorotnikov, O. A. Efremova, I. N. Novozhilov, V. V. Yanshole, N. V. Kuratieva, K. A. Brylev, N. Kitamura, Y. V. Mironov, M. A. Shestopalov, J. Mole. Struc. 2017, 1134, $237-243$.

[32] A.K.D. Dime, H. Cattey, D. Lucas, C.H. Devillers, Electrosynthesis and X-ray Crystallographic Structure of Zn-II meso-triaryltriphenylphosphonium porphyrin and structural comparison with $\mathrm{Mg}$-II meso-triphenylphosphonium porphine, Eur. J. Inorg. Chem. 44 (2018) 4834e4841.

[33] M. Berthelot, G. Hoffmann, A. Bousfiha, J. Echaubard, J. Roger, H. Cattey, A. Romieu, D. Lucas, P. Fleurat-Lessard, C.H. Devillers, Oxidative C-N fusion of pyridinyl-substituted porphyrins, Chem. Commun. 54 (2018) 5414e5417.

[34] T. Ogawa, Y. Nishimoto, N. Yoshida, N. Ono, A. Osukua, One-pot electrochemical formation of meso, meso-linked porphyrin arrays, Chem. Commun. (1998) 337e338.

[35] T. Ogawa, Y. Nishimoto, N. Yoshida, N. Ono, A. Osukua, Completely regioselective synthesis of directly linked meso meso and meso, $\pi$ porphyrin dimers by one-pot electrochemical oxidation of 
metalloporphyrins, Angew. Chem. Int. Ed. 38 (1999) $176 \mathrm{e} 179$.

[36] A.K.D. Dime, C.H. Devillers, H. Cattey, B. Habermeyer, D. Lucas, Control over the oxidative reactivity of metalloporphyrins. Efficient electrosynthesis of meso, meso-linked zinc porphyrin dimer, Dalton Trans. 41 (2012) 929e936.

[37] J. Fajer, Structural effects in chemistry and biology, J. Porphyr. Phthalocyanines 4 (2000) 382e390.

[38] J.A. Shelnutt, X. Song, J.G. Ma, S.L. Jia, W. Jentzen, C.J. Medforth, Nonplanar porphyrins and their significance in proteins, Chem. Soc. Rev. 27 (1998) 31e42.

[39] K.M. Barkigia, M.D. Berber, J. Fajer, C.J. Medforth, M.W. Renner, K.M. Smith, 448 M. Boudiaf et al. / Electrochimica Acta 309 (2019) 432e449 Nonplanar porphyrins. X-ray structures of $(2,3,7,8,12,13,17,18$-octaethyl- and -octamethyl-5,10,15,20-tetraphenylporphinato)zinc(II), J. Am. Chem. Soc. 112 (1990) 8851e8857.

[40] L.D. Sparks, C.J. Medforth, M.S. Park, J.R. Chamberlain, M.R. Ondrias, M.O. Senge, K.M. Smith, J.A. Shelnutt, Metal dependence of the nonplanar distortion of octaalkyltetraphenylporphyrins, J. Am. Chem. Soc. 115 (1993) 581e592.

[41] M.O. Senge, M.W. Renner, W.W. Kalisch, J. Fajer, Molecular structure of (5,10,15,20-tetrabutyl$2,3,7,8,12,13,17,18$-octaethylporphyrinato)nickel(II)d correlation of nonplanarity with frontier orbital shifts, J. Chem. Soc. Dalton Trans. (2000) 381e385.

[42] F. D'Souza, M.E. Zandler, P. Tagliatesta, Z. Ou, J. Shao, C.E. Van Caemelbecke, K.M. Kadish, Electronic, spectral, and electrochemical properties of $\left(\mathrm{TPPBr}_{\mathrm{x}}\right) \mathrm{Zn}$ where $\mathrm{TPPBr}_{\mathrm{x}}$ is the dianion of bbrominated-pyrrole tetraphenylporphyrin and x varies from 0 to 8, Inorg. Chem. 37 (1998) 4567e4572. [43] M.E. Anderson, A.G.M. Barrett, B.M. Hoffman, Super-charged Porphyrazines: synthesis and physical properties of octacationic tetraazaporphyrins, Inorg. Chem. 38 (1999) 6143e6151.

[44] C. Bernard, J.P. Gisselbrecht, M. Gross, E. Vogel, M. Lausmann, Redox properties of porphycenes and metalloporphycenes. A comparison with porphyrins, Inorg. Chem. 33 (1994) 2393e2401.

[45] M. Kasha, Relation between exciton bands and conduction bands in molecular lamellar systems, Rev. Mod. Phys. 31 (1959) 162e169.

[46] J.L. Sessler, M. R. Johnson, S. E. Creager, J. C. Fettinger, J. A. Ibers, Synthesis and characterization of quinone-substituted octaalkyl porphyrin monomers and dimers, J. Am. Chem. Soc. 112 (1990) $9310 \mathrm{e} 9329$.

[47] G.J. Abhilash, J. Bhuyan, P. Singh, S. Maji, K. Pal, S. Sarkar, NO2-Mediated meso-hydroxylation of iron(III) porphyrin, Inorg. Chem. 48 (2009) 1790e1792.

[48] C. Inisan, J.Y. Saillard, R. Guilard, A. Tabard, Y. Le Mest, Electrooxidation of porphyrin free bases: fate of the p-cation radical, New J. Chem. (1998) $823 \mathrm{e} 830$.

[49] Z. Huo, I. Azcarate, R. Farha, M. Goldmann. H. Xu, B. Hasenknopf, E. Lacôte, L. Ruhlmann, J. Solid State Electrochem, 2015, 19, 2611-2621. 